\title{
Panlongcheng, Zhengzhou and the Movement of Metal in Early Bronze Age China
}

\author{
Ruiliang Liu' ${ }^{1}$ - A. Mark Pollard' ${ }^{1}$ Jessica Rawson ${ }^{1} \cdot$ Xiaojia Tang $^{1} \cdot$ Peter Bray $^{1}$. \\ Changping Zhang ${ }^{2}$
}

Published online: 27 November 2019

(c) The Author(s) 2019

\begin{abstract}
The role of Panlongcheng-a walled settlement on the Yangtze River with obvious links to the Erligang capital at Zhengzhou, $\sim 500 \mathrm{~km}$ to the north-in early Bronze Age China has been the subject of much debate. Panlongcheng is a typical Erligang site ( 1500-1300 BC), with evidence for people of elite status, unlike any other site apart from Zhengzhou itself. The tombs and bronzes at Panlongcheng, as well as other materials, closely resemble those at Zhengzhou. Why was Panlongcheng established along the Yangtze River, and what were the Erligang elites doing there? Considering the rich copper deposits in this area, it is widely assumed that the major function of Panlongcheng was to ship metal to Zhengzhou, and in return to receive bronze vessels from Zhengzhou. The purpose of this paper is to revisit this discussion through a re-evaluation of the scientific data on the bronzes from each site. A series of differences and similarities in the chemical and isotopic compositions of the metal objects at Panlongcheng and Zhengzhou are identified, suggesting that the relationship was more complex than was previously thought. In this light, despite a close social and presumably political affiliation with Zhengzhou, Panlongcheng appears likely to have had its own metal-casting capability, rather than having to rely completely on finished objects imported from Zhengzhou. This discovery encourages scholars to re-consider the metal supply network and the underlying political landscape in early dynastic China, shifting from a linear model to a complex but probably more realistic one.
\end{abstract}

Keywords Bronze Age China · Panlongcheng $\cdot$ Zhengzhou $\cdot$ FLAME $\cdot$ Copper $\cdot$ Tin

Ruiliang Liu

ruiliang.liu@arch.ox.ac.uk

1 School of Archaeology, University of Oxford, Oxford OX1 3TG, UK

2 School of History, Wuhan University, Wuhan 430072, China 


\section{Introduction}

The making of bronzes by complex piece-mould casting, particularly ritual bronze vessels, is one of the hallmarks of the Bronze Age on the Central Plains of China. The first evidence of it comes from Erlitou Phase II (1671-1622 cal BC, 95.4\% confidence; Fig. 1). The recent comparative work led by Rawson in Oxford, which is primarily based on the site size and infrastructures of the principal Neolithic centres in China (3rd and 2nd millennium BC), together with a chronology deriving from a large radiocarbon Bayesian modelling, suggests a relatively dramatic change in geographic, technological and social patterns (Zhang et al. 2019). The decline and disappearance of major archaeological cultures along the Yangtze River, for instance, Liangzhu, Shijiahe, and Baodun, coincides with the rise of the northern borderlands (e.g. Shimao) and further indicates perhaps substantial shifts in population. Whilst the cause(s) of these changes have been extensively debated in China, it is probably reasonable to believe that if these major Neolithic powers had continued to survive the Chinese Bronze Age would have been completely different. Against this backdrop, the ascendency of the Bronze Age culture at Erlitou can be considered a key fusion, which successfully cemented two completely unrelated crucial technological traditions. The northern groups were influenced by the steppe metal production tradition, originating somewhat to the west (Linduff and Mei 2014), although the

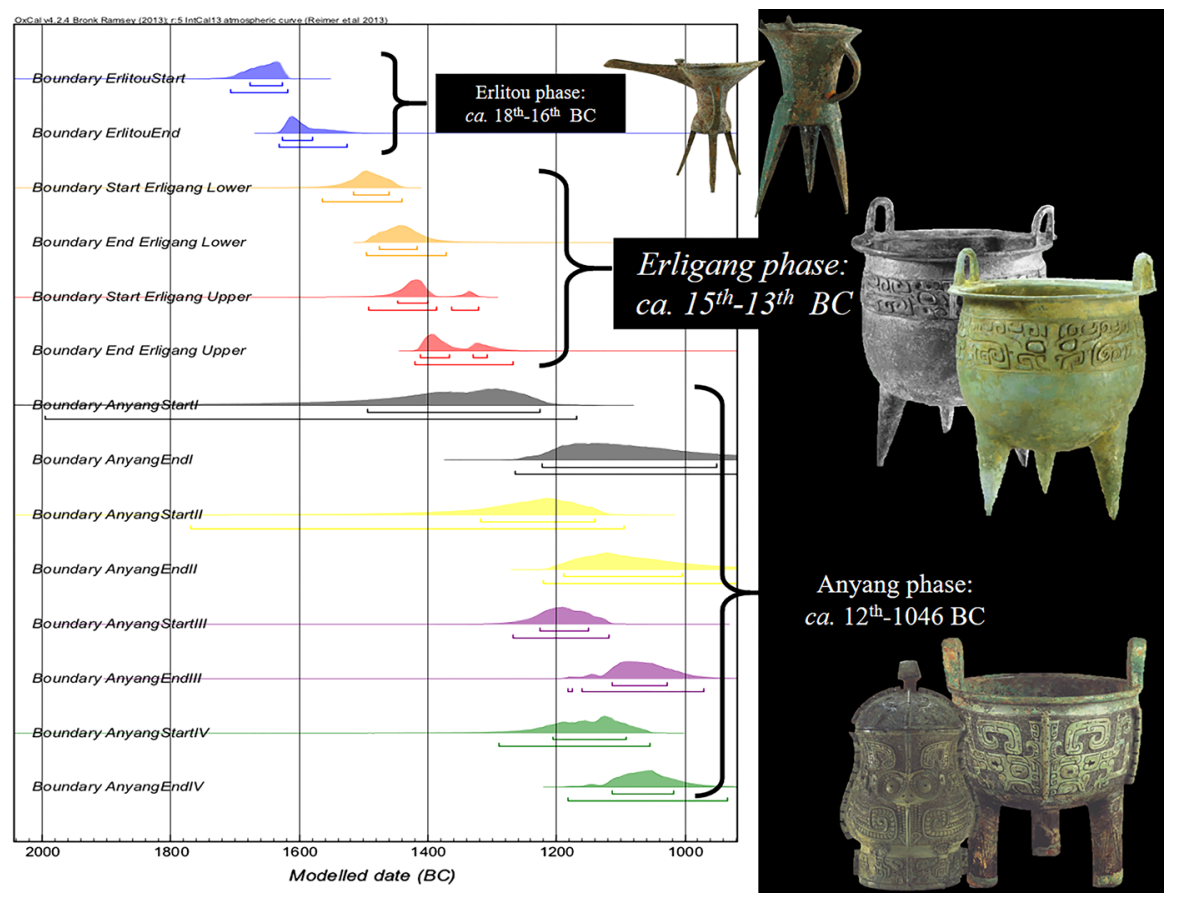

Fig. 1 Chronological framework of the early Bronze Age in the Central Plains, China. (After Liu 2016, p. 19) 
technology and typological repertoire were completely different from those that were subsequently developed in China. The eastern groups, mainly in the Neolithic Shandong peninsular, developed a highly refined pottery tradition, exemplified by egg-shell-thin black pottery vessels. The bronze casters at Erlitou thus synthesized the metallurgy from the northern borders and the long-standing Neolithic tradition of creating complex ceramic ritual vessels for ceremonies and burial. The outcome, namely those large and complex bronze ritual vessels, continued to be a distinctive feature throughout the Chinese Bronze Age (Zhang et al. 2019).

The process of casting bronze vessels developed at Erlitou was inherited, improved and standardized by the subsequent Erligang people. This is the name given to the groups who established the massive walled site, the remains of which are now under the modern city of Zhengzhou, whose archaeology is described below. The status of Zhengzhou in Chinese metallurgical history is extremely high as a number of technological and social practices were firmly established here, such as producing metal objects with targeted recipes (Pollard et al. 2019a, b) or using bronze ritual vessels in sets, an outstanding characteristic of China (Bagley 1999; Rawson 1999). The spread of Erligang-type activities, known as the Erligang culture (c. 1500-1300 BC, Fig. 1), can be traced by way of sites that have revealed pottery or bronzes in the general Erligang style (Fig. 2). The shading illustrates the development of the impact of Erligang type pottery. Bronze vessels are very rare at the majority of the Erligang sites known outside Zhengzhou, with the major exception being Panlongcheng on the Yangtze River, far to the south. If the spread of ceramics can genuinely be regarded as indicating social, economic and political contacts, then the overall area may be regarded, as some authorities have suggested, as a state or even an empire. The precise nature, origin and production of the Panlongcheng bronze vessels is therefore at the heart

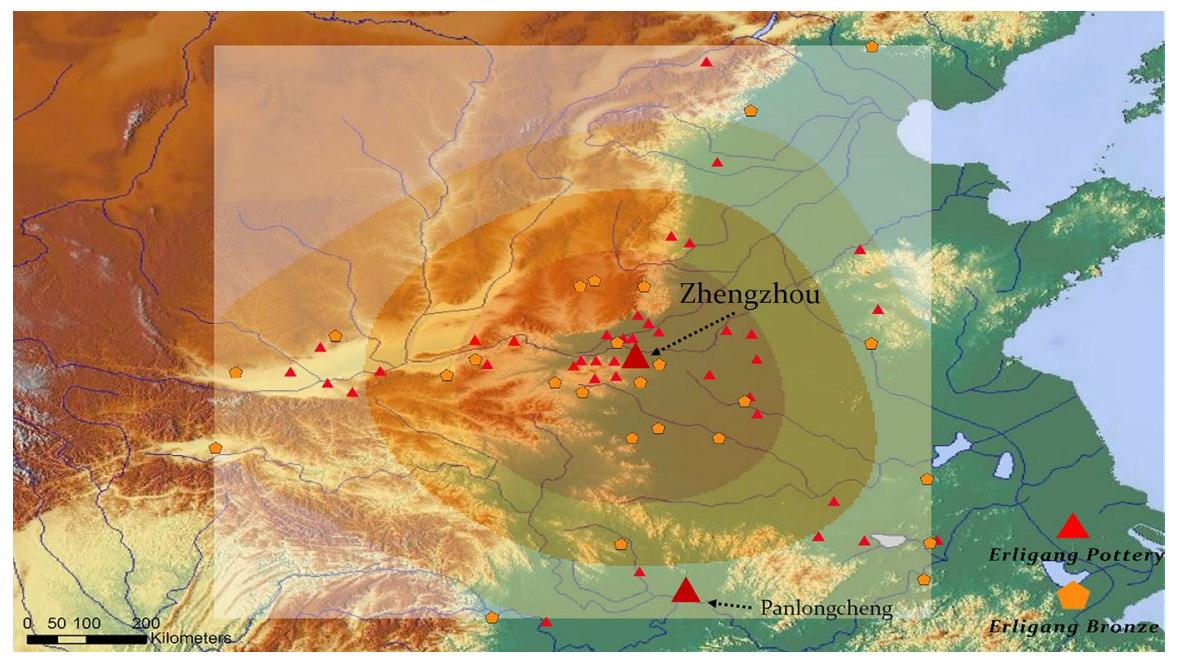

Fig. 2 The Erligang world (the gradation of the orange colour is the density analysis based on the sites which have pottery in the Erligang style) (Color figure online) 
of the debate over the Erligang culture, alongside their metallurgical implications (Jiang 1976; Bagley 1977, 1999, pp. 168-171; Liu and Chen 2009, pp. 116-119; Wang 2014).

Both Zhengzhou and Panlongcheng were discovered in the early 1950s (Lan 1955; An 1954), and since then have posed a major challenge to those trying to interpret the nature of the Erligang world. Panlongcheng (described in more detail below) is located near the northern bank of the Yangtze River, around $500 \mathrm{~km}$ south of Zhengzhou, and remote from the core area of the Erligang culture shown in Fig. 2. Although these two sites are no longer the only known Erligang walled settlements, so far they remain the only two with clear evidence for elite inhabitants, who required not only bronzes in the Zhengzhou style but also a palatial complex, tomb structures, and pottery similar to that seen at Zhengzhou (Zhang 2014a, b). What is the nature of the relationship between these two sites? More specifically, what was the role of Panlongcheng in relation to Zhengzhou, and why was it sufficiently important for elites to live there using Erligang forms of ritual? The most frequent explanation is that Panlongcheng was an 'outpost' established by the central Shang authorities in Zhengzhou, in order to acquire copper from the mines operating at that time along the middle and lower Yangtze. Hence the movement of metal between these two sites forms probably the most important component of metal circulation in early dynastic China (see e.g. Jiang 1976; Bagley 1977, 1999; Song 1983; Gao 1985; Liu and Chen 2001, 2009, pp. 116-119, 2012, pp. 285-289; Li 2001; Xu 2003; Hubei Institute of Archaeology 2001, pp. 502-504; Chen 2014; Zhang 2014a; Shelach-Lavi 2015, p. 2; Fang 2016; Shi 2016).

A number of questions arise from the observation that Zhengzhou and Panlongcheng have similar bronzes (e.g. shapes, motifs and casting technologies). Specifically:

- Were the bronzes made at Zhengzhou and shipped to Panlongcheng?

- To achieve this, was copper mined near Panlongcheng and sent to Zhengzhou?

- Or did Panlongcheng have its own metal casting facility? If so, why are the bronzes so like the ones at Zhengzhou?

This paper attempts to assess the likelihood of Panlongcheng being a "copper supply depot' for Zhengzhou by comparing the metal used at the two sites. Unfortunately, the key Erligang-style ritual bronze objects found at Panlongcheng have yet to be chemically analyzed, so we cannot directly compare the most important sets of objects. However, a reasonable number of analyses have been reported from broken objects at both sites, with recognizable typology and relatively comprehensive analyses (alloying, trace elements, and lead isotopes: Tian 2013; Chen et al. 2001; Sun et al. 2001). These are sufficient to start a comparative study and begin to answer the questions set out above. We have therefore applied the methodology developed as part of the FLAME project (Bray et al. 2015; Pollard et al. 2017a, b, 2019a, b) to reveal similarities and differences between the chemistry and lead isotope composition of assemblages of objects. The hypothesis to be tested is simple: if Panlongcheng is supplying copper to Zhengzhou, then the copper found at both places should be the same. If it is substantially different, then we must modify the idea that 
one of the functions of Panlongcheng was to channel copper from the Yangtze River valley, and seek other explanations for the clear linkages between these two sites.

\section{Reviewing the Archaeological Background: Zhengzhou, Panlongcheng and the Erligang World}

The Neolithic period in China traditionally closes with the rise of Erlitou, the first major bronze production centre on the Central Pains. Erlitou emerged as the main survivor after the majority of the preceding eastern and central Neolithic cultures had declined and disappeared (Zhang 2017; Zhang et al. 2019). The first major expansion following the rise of Erlitou was the spread of Erligang types of material culture. The name Erligang is taken from a site discovered in 1950 in the southeastern part of Zhengzhou. Whilst a number of early papers were published on the detailed chronological divisions of the Erligang culture at Zhengzhou (An 1954; J. An 1973; Zou 1956; Henan Cultural Bureau 1959), it is now widely accepted that it can be divided into four phases (Erligang Lower Phase I/II and Erligang Upper Phase I/II).

The first formal excavation was conducted in the autumn of 1952 (An 1954). In the following 3 years, a range of excavations were carried out around the site, yielding numerous small tombs - containing mostly pottery, but also bronzes and jadesone pottery kiln and two bronze workshops. Trench stratigraphy and the typological seriation of pottery and bronze demonstrated that this site was occupied before Anyang, renowned since its excavation in the late 1920s as the last capital of the Shang (c. 12th C. BC-1046 BC).

In 1955, a solid layer of rammed earth was discovered during the survey of Zhengzhou. Local archaeologists gradually realized that it was part of a substantial city wall. Although it is extremely difficult to excavate the site, as it lies beneath the modern city of Zhengzhou, during the 1960s and 1970s a large amount of work was focused on revealing its layout (IA CASS 2003, p. 35). Massive walls of around 2-3 $\mathrm{m}$ in height and at least $10 \mathrm{~m}$ wide survive in many places. The inner walled area is around $3 \mathrm{~km}^{2}$ and the outer one was substantially larger, occupying over $25 \mathrm{~km}^{2}$. Following the discovery of the walls, a number of palatial complexes were found, ranging in area from several hundred $\mathrm{km}^{2}$ to over one thousand. Their varying structures suggest different functions. Multiple workshops for bronze, pottery and bone implements have also been excavated, within or near to the inner walled area.

Since 1954, two bronze foundries have been found at Zhengzhou. That named Nanguanwai, located in the north of the site, occupies around $21,000 \mathrm{~m}^{2}$. A considerable body of evidence, including metallurgical waste, fragmented moulds and crucibles, supports the identification of the site as a bronze foundry. Its period of use ranges from Erligang Lower Phase II to Upper Phase I (c. 1500-1400 BC). The other foundry site, named Zijinshan, was excavated in the same year, and is located against the southern side of the inner wall. At around $2000 \mathrm{~m}^{2}$, it is dramatically smaller than Nanguanwai, but this may be due to the destruction of part of the site by modern construction. Zijinshan was only active in phase I of the Upper Layer of Erligang (Henan Institute of Archaeology 2001, pp. 307-383). Apart from providing 
similar evidence for metallurgical activity as found at Nanguanwai, Zijinshan also yielded blocks of copper and lead. Samples of copper ore (malachite) have also been found, containing traces of radiogenic lead, the significance of which is discussed below. The types of mould found indicate that both foundries were heavily focused on the production of tools, rather than the more prestigious ritual bronzes.

So far, no large elite tombs have been found at Zhengzhou. The majority of bronzes have either come to light by chance or have been excavated from hoards (Henan Institute of Archaeology and Zhengzhou Institute of Archaeology 1999; Fang 1999; Henan Institute of Archaeology and Zhengzhou Museum 1983; Henan Provincial Museum 1975). The large ding (鼎) vessels in Fig. 3 were found in one of these hoards (Xiangyang huicu shipinchang). They are more than $80 \mathrm{~cm}$ in height, suggesting that the casters and patrons at Zhengzhou had exact requirements for their ritual practice in terms of the size and display potential of their bronze vessels. The five objects in the lower line of Fig. 3 are much smaller, but were also derived from a single archaeological context, this time a small tomb in the Baijiazhuang cemetery. They display clear similarities with the bronze objects recovered from, for instance, tomb M2 at Lijiazui in Panlongcheng (Fig. 4), a high-elite tomb dated to the middle phase of Panlongcheng (see below).

So far, there are two comprehensive reports that offer a record of the excavations and subsequent study of Zhengzhou. That published in 1959 illustrates the general scope of Zhengzhou archaeology with foci on the description of stratigraphy and pottery (Henan Cultural Bureau 1959). Thanks to the further 40 years of excavations by local archaeologists, the second one presents a much greater amount of material,

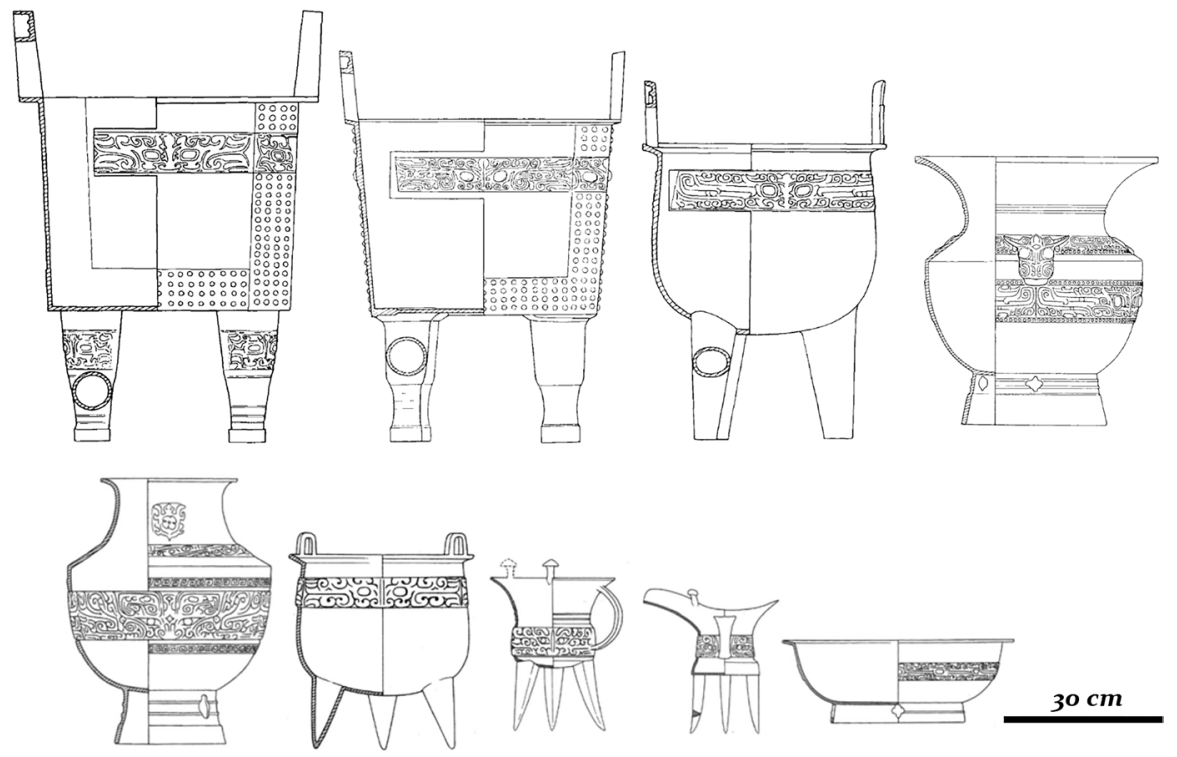

Fig. 3 Objects from Zhengzhou. The upper line comes from the same hoard at Zhengzhou and the lower one comes from the tomb C8M2 at Zhengzhou Baijiazhuang (Henan Institute of Archaeology and Zhengzhou Institute of Archaeology 1999) 


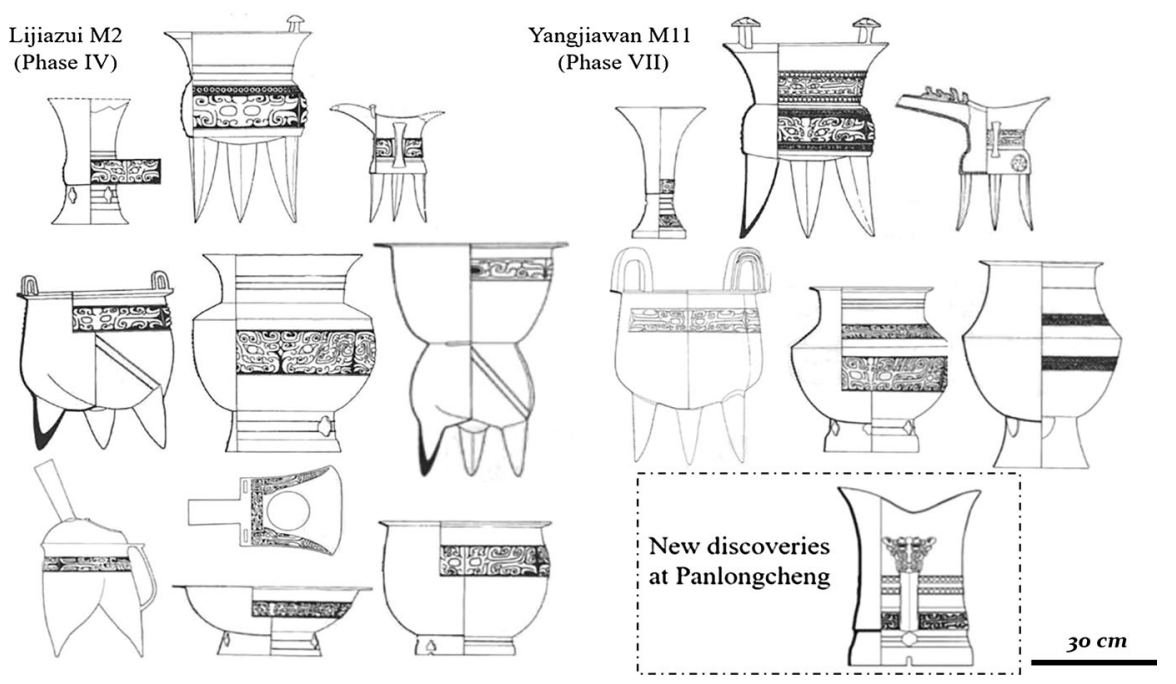

Fig. 4 Bronze objects at Panlongcheng (Hubei Institute of Archaeology 2001)

and lays an important foundation for wider scholarly discussions (Henan Institute of Archaeology 2001). Almost all of the major findings mentioned above, such as the palaces and bronze foundries, are systematically presented in this second report.

Since its discovery, the question of Zhengzhou and its relationship with other regions has been much discussed. Of foremost interest is the definition of the Erligang culture and an assessment of its expansion (Bagley 1977, 1999; IA CASS 2003, p. 13; Liu and Chen 2009, p. 102; Wang 2014; Fang 2016). During the expansion period, western Henan was densely occupied by peoples who had adopted Erligang practices. In addition to Zhengzhou, several other sites were enclosed by great walls of rammed earth. The largest of these is Yanshi Shang, with an area of c. $1.9 \mathrm{~km}^{2}$ (Du and Wang 2004, p. 446). The other three (Yuanqu: $0.133 \mathrm{~km}^{2}$ [National Museum of Chinese History et al. 1996, p. 14]; Dongxiafeng: size unknown [IA CASS 1988]; and Fucheng: $0.09 \mathrm{~km}^{2}$ [Yuan and Qin 2000]) are considerably smaller. In addition, numerous smaller settlements have been found around these large walled sites. These suggest that the Erligang culture had a hierarchical social structure. In modern Chinese archaeological studies, one can often find this culture equated with the early Shang dynasty as described in the historical texts (Zhengzhou=the Erligang culture=Early Shang), and the consequent argument that Zhengzhou and Yanshi were two of the capitals recorded in later textual materials (An 1961; Zou 1978). Although this is still extensively debated, these claims provide a vivid illustration of the importance attached to Zhengzhou.

Beyond the core area of the Central Plains, pottery and bronzes are the two most common indicators of whether or not a site belonged to the Erligang culture, as either a direct subordinate or a local variant. As shown in Fig. 2, the expansion of the Erligang culture, which is to a large extent defined by pottery, covered a vast area (around a million square kilometres). Kernel-density patterns based on the distribution of the Erligang-style pottery (Fig. 2) indicate that the major 
directions of expansion were east, west and south. The eastern and western movement is well demonstrated by the sites of Daxinzhuang in Shandong and Laoniupo in Shaanxi (Liu 2002; Fang 2004). But of all of these expansions, that to the south was the most impressive because it reached the Yangtze River and even beyond.

The discovery of a typical Erligang period site at Panlongcheng on the Yangtze River came as a considerable surprise (Gao 1981). The site was first found in the autumn of 1954 in an archaeological survey that took place alongside local floodcontrol projects (Lan 1955). A few randomly recovered pottery sherds showed similarities with Zhengzhou and Anyang pottery. Three years later, several bronze fragments (one Jia 單 vessel and a few weapons) were discovered at Panlongcheng and dated to the Erligang period (Guo 1958; interestingly, these objects were dated to Western Zhou in Guo's original paper, but the editor noted that they actually belonged to the Erligang period). Walls, tombs and bronze ritual vessels were subsequently excavated in 1963, 1974, 1976, 1979-1984, and 1989 and have now revealed a site that has much in common with the Erligang period capital at Zhengzhou (Hubei Institute of Archaeology 2001, pp. 6-10). The first major assessment of the importance of the site to be published in the West was by Bagley (1977). He noted that

unquestionably the chief significance of the Shang site at P'an-lung-ch'eng (Panlongcheng) lies in its concrete demonstration of the southerly extension of the Shang state ... The cultural remains at P'an-lung-ch'eng are so entirely free of any sort of provincialism, however, that the city figures in the archaeological record as a 'Shang site' in exactly the same measure as Chengchou (Zhengzhou) ... and it would be difficult to explain such exact similarity without assumption, for all practical purposes, of unified political control. This is not to rule out the possibility that P'an-lung-ch'eng was a sort of isolated military outpost in hostile territory (Bagley 1977, p. 210).

Originally, the site was on a promontory, surrounded by the waters of the Fu River, which runs into the Yangtze, although the water level may have been lower than at present, allowing for greater land-based connections. Several phases of excavation since the 1950s have enabled archaeologists to construct a reasonably clear picture of Panlongcheng. It is divided into two parts by the rammed earth walls that enclose the middle of the site. The chief discovery inside this area is of the two palaces ( 2 ha) found in 1974. Most of the known tombs are outside the walls, including those of the highest rank, such as Lijiazui M1 and M2 (excavated in 1974), or Yangjiawan M11 (excavated in 1989). Their rich contents, including dozens of bronzes, jades and high-fired pottery, signify the high social status of their occupants. Both the earlier Liujiazui M2 and the later Yangjiawan M11, reported in the original archaeological report as the fourth and seventh phase of Panlongcheng respectively (Table 1), display a standard set of ritual bronze vessels ( $g u+j u e+j i a+$ others: Fig. 4$)$, comparable to the sets found in the Central Plains, and central to Shang identity (Zhang 2014a, b). The connection between Zhengzhou and Panlongcheng is self-evident with a comparison of the shapes, decoration and casting techniques of their bronzes (Figs. 3, 4). More detailed comparisons using other sources of archaeological 
Table 1 The correspondence between the seven chronological phases at Panlongcheng and those of Erlitou and Erligang (Hubei Institute of Archaeology 2001, pp. 442-446)

\begin{tabular}{lllllll}
\hline Panlongcheng phase & I & II & III & IV-V & VI & VII \\
\hline Erlitou II phase & $\sqrt{ }$ & & & & & \\
Erlitou III phase & & $\sqrt{ }$ & & & & \\
Erlitou IV to Erligang lower I phase & & & $\sqrt{ }$ & & & \\
Erligang upper I phase & & & $\sqrt{ }$ & & \\
Erligang upper II phase earlier & & & & & $\sqrt{ }$ & $\sqrt{ }$ \\
Erligang upper II phase later & & & & & & \\
\hline
\end{tabular}

evidence, such as pottery, tomb structures and building technologies, can be found in Zhang (2014a, b).

The discovery of several tombs with sets of bronze ritual vessels very like those at Zhengzhou has raised a number of major questions about the relationship of Panlongcheng with Zhengzhou. It has long been argued that since sites such as Zhengzhou in the Central Plains do not have direct access to any nearby copper mines, the function of the outpost at Panlongcheng was to secure copper and transport it north to Zhengzhou (see references above). The expansion and retraction of Erligang culture appears to have taken place over about 200 years. This rapid rise and fall, together with the assumed need to secure natural resources, has been taken as evidence for a military occupation and an empire model for Erligang (e.g. Bagley 1977, 1999; Wang 2014). More recently, other explanations for the Erligang expansion have been advanced, such as models of local lordships, trade diaspora, traditional colonial dominance or ritual landscape, which are collected in the conference proceedings entitled Art and Archaeology of the Erligang Civilization (Steinke and Ching 2014).

\section{Reviewing Scientific Analyses of Bronzes: Metal Provenance, Local Production and Inter-regional Relationships}

Archaeological work in China has revealed a Bronze Age world completely different from that of Europe or Russia. The use of bronze came late to central China, but when it arrived, it rapidly attained a scale and complexity unseen in the immediate neighbouring arc, or the steppe to the west (Rawson 2015, 2017). For example, the total weight of metal discovered in Fu Hao's tomb, the only intact royal Shang tomb so far discovered in Anyang, is 1.6 tons (IA CASS 1980). Giving that Anyang is remote from the major sources of copper, tin or lead, supporting such an enormous scale of production must have required a considerable amount of organization. Exploring the sources of metal in China is critically important to an understanding of the nature of this organization. However, compared with Russia and Europe, alloy composition (i.e., $\mathrm{Cu}, \mathrm{Sn}$ and $\mathrm{Pb}$ ) has been the major focus of metallurgical analysis in China. As a result, the data on minor and trace elements is relatively slight (Liu et al. 2015). 
The very strong stylistic similarities between the bronzes of Zhengzhou and Panlongcheng has led to a long-standing question about the status of bronze production at Panlongcheng (Bagley 1977; Zang 2003). Most of the previous literature has assumed that copper was transported north from Panlongcheng, and that the bronzes were cast at Zhengzhou and transported back to the elites at Panlongcheng. For instance, Liu and Chen (2009, p. 117) state that 'Judging by the lack of evidence for casting ritual vessels at Panlongcheng and the stylistic similarities between the bronzes found at Panlongcheng and major Erligang sites in the north, these ritual vessels, mainly found in elite burials, were probably cast at Zhengzhou and then imported to Panlongcheng'. As the ceramic-mould technology required to cast elite bronzes is highly complex, this is not an unreasonable suggestion. Alternatively, skilled bronze casters might have been dispatched from Zhengzhou to work in the south, in which case evidence for a substantial casting workshop must eventually come to light at Panlongcheng (Kane 1974; Bagley 1977, 2016; Chen 2015, pp. 164-186; Wang 2016).

A variety of divergent opinions about the purported 'metallurgical remains' at Panlongcheng have been published (Wang 2016; School of History of Wuhan University et al. 2016). Based on the new phase of excavation, the chief excavator, Zhang Changping, has pointed out that an increasing number of traces indicate the existence of a local foundry for bronze casting in the section of Xiaozui (Fig. 5). Portable XRF analysis shows that the soil in some areas of Xiaozui contains copper levels ten times higher than elsewhere. Some clay pieces may be moulds (School of History of Wuhan University et al. 2016). Very high-quality stone moulds for knives were also found during the survey adjacent to Xiaozui (Han 2016). Large pottery fragments (presumably crucibles) containing copper waste and thick layers of charcoal have also been discovered in the trenches around Yangjiawan and Yangjiazui (Fig. 5; Qiu 2016). Without any doubt, a local bronze production system of some sort existed at Panlongcheng, but as yet there is no evidence for the production of elite bronze vessels.

Three sources of scientific evidence have been used in an attempt to decide whether the bronzes found at Panlongcheng were made locally or in Zhengzhou. One approach is to study the chemistry of the clay casting cores remaining in the bronzes; a second is to chemically analyze the metal itself; and a third is to conduct lead isotope analysis on the metal.

The analysis of the clay cores in the legs and handles of two Panlongcheng bronzes, obtained during the process of conservation, shows a difference in concentrations of calcium and magnesium as compared to cores from Anyang, Zhengzhou, Houma and Zhouyuan (Nan et al. 2008). This distinction could be due to the use of clay from different geological environments (which would suggest that the bronzes found at Panlongcheng were not cast in the Central Plains), or it could be the result of different degrees of anthropogenic processing of the clay. It could also be a reflection of random variation within the clay source.

Some comparative studies based on trace elements in the bronzes can be found in work by Chen and colleagues (Chen et al. 2001). Using principal components analysis (PCA), they show differences between the objects found at Panlongcheng, the copper ingots from Tonglvshan (a major Bronze Age mining site 

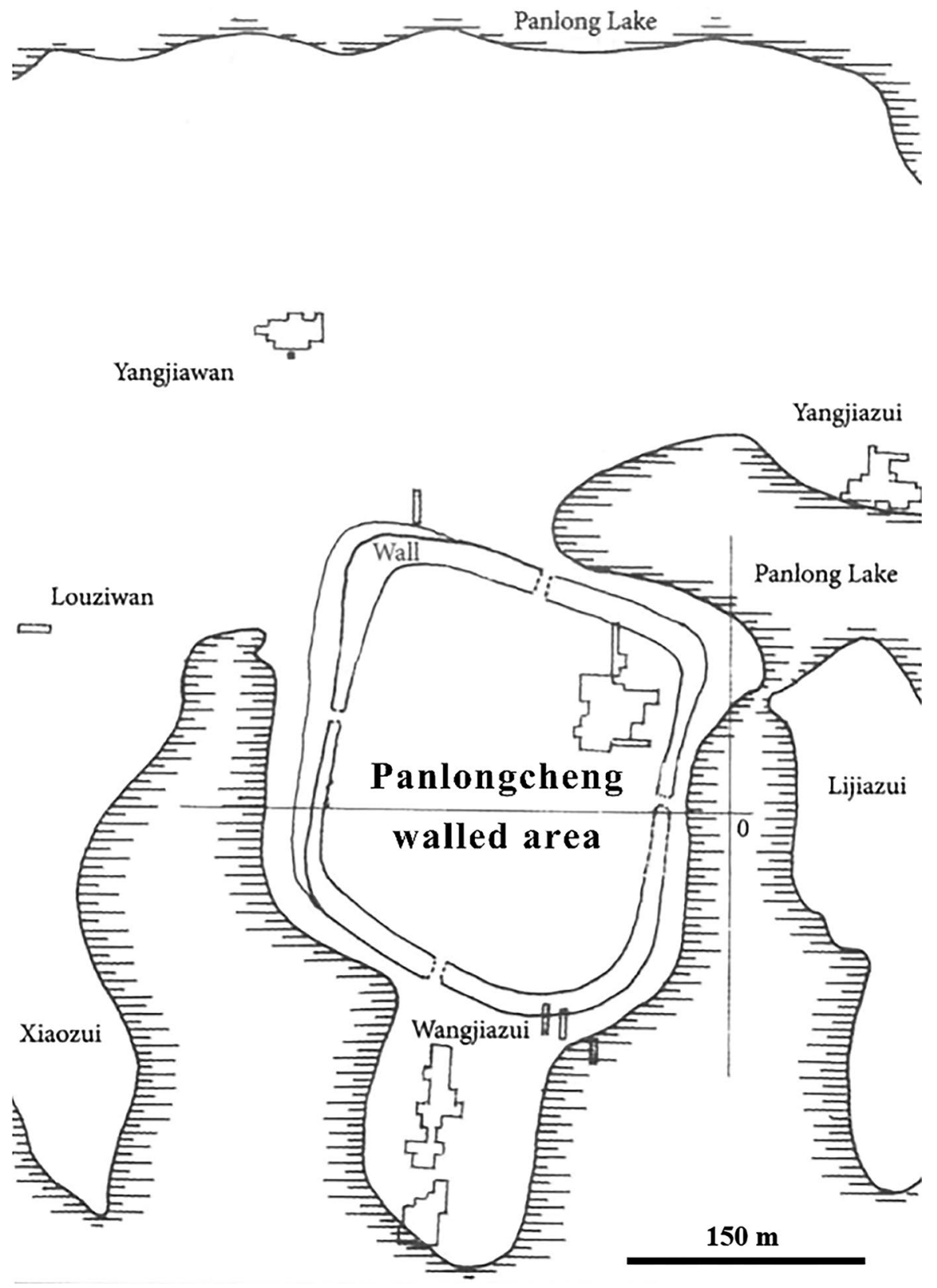

Fig. 5 Overview of the Panlongcheng site (from Zhang 2014b, p. 53)

on the Yangtze River) and a number of bronzes collected by the local E'zhou museum dated to the late Shang, Warring States, Han dynasty, Six dynasties and Tang. In this work, it is interesting to note that: 
1. the Panlongcheng objects are closely clustered by PCA, but differ significantly from the two samples of ore from Tonglvshan, which implies that the copper was not derived from these sites;

2. the Panlongcheng objects show strong similarity to the late Shang objects from the E'zhou museum, but increasingly differ from those of later periods (Warring States, Han dynasty, Six dynasties and Tang; Chen et al. 2001). Chen and colleagues suggest a continuity of copper supply at Panlongcheng from the Erligang period to the end of the Shang dynasty.

From a lead isotopic study of the bronzes (Peng et al. 2001; Sun et al. 2001), both radiogenic and common lead are detected in the objects found at Panlongcheng (these terms are explained below). The tentative conclusion is that the lead supply of Panlongcheng may have been based on more than one source. This argument is plausible providing that the radiogenic and common lead isotopes derived from different places, which is not necessarily the case. As explained below, we cannot establish by lead isotopes alone whether the objects from Panlongcheng were made at Zhengzhou or Panlongcheng, since both radiogenic and common lead were used at both sites.

\section{The Oxford System for Interpreting Chemical and Isotopic Data in Chinese Bronzes: A Critique}

This paper chooses to focus on the bronze objects themselves and try to contribute to this discussion by using the published metal chemical analyses from Zhengzhou and Panlongcheng and the FLAME characterization system. FLAME (the FLow of Ancient Metal across Eurasia) is a research project funded by the European Research Council, focused on the chemical and isotopic composition of copper alloy objects across Eurasia during the Bronze Age. The aim is to use variations in the spatial and chronological distributions of copper and its alloys as a proxy for understanding the movement of metals as well as the underlying relationships between different societies across Bronze Age Eurasia. In order to do this, we attempted to expand the focus of studies from a purely 'provenance-based' approach towards a broader characterization framework ('form and flow'). This acknowledges variation in the life histories of both objects and materials (Bray et al. 2015; Pollard et al. 2017a, b), including the possibility that copper may be recycled, re-alloyed or generally reused. This reassessment of archaeological metal chemistry is underpinned by a new set of interpretative tools designed to characterize change in the archaeometallurgical record (namely trace element data, major-alloying data and lead isotope data), and is conducted within a Time-GIS framework. Detailed explanations have been published in Bray et al. (2015) and Pollard et al. (2017a). Therefore, here we only offer a tightened version for general readers, focusing on how these interpretative tools can be applied to Bronze Age China.

For the trace (minor) element data, a two-stage method has been developed. The first stage divides the objects in a defined metal assemblage into 16 'copper groups' based on the presence or absence of four trace elements (arsenic [As], antimony 
[Sb], silver [Ag] and nickel [Ni], using $0.1 \%$ as the cut-off between presence and absence: Table 2). These four elements are selected for two reasons. Firstly, they are the four most commonly reported trace elements in the literature, and focusing on them allows us to use as much of the legacy data as possible. Secondly, the concentration of arsenic and antinomy in bronzes decreases in a high-temperature oxidizing atmosphere, whereas silver and nickel remain unaffected (McKerrell and Tylecote 1972). Hence these four trace elements capture a range of thermodynamic behaviours, which are useful for tracking the history of a unit of metal following the smelt, particularly processes such as recycling and mixing. Before allocating objects to copper groups on the basis of presence/absence of the trace elements, we mathematically 'strip out' the alloying elements ( $\mathrm{Pb}$ and $\mathrm{Sn}$ in this case), on the initial assumption that the trace elements are associated with the copper and not the alloying elements. Not to do so would risk dilution of the trace elements in objects which contain large amounts of alloying metal. The 16 copper groups are essentially one characterization method of chemistry and the closest parallel in archaeology might be pottery typology (characterization but on forms or motifs).

Following the first stage of classification using presence and absence, the second stage assesses the patterns and structure within the groups. We commonly plot on a map the proportions of different copper groups against time and space for comparative purposes (ubiquity analysis), or use statistical tools such as elemental profiles, XY scatter plots, or kernel density analysis to visualize and test the differences present in the raw data. The distribution of a chemical element within a copper group assemblage is also useful for characterizing the processes that metal had undergone. As a simple example, prime arsenical copper (Copper Group [hereafter CG] 2) might show high levels of arsenic in a bell-curve ('normal') distribution, while the same copper that has been repeatedly melted shows a curve skewed to low values, due to the oxidative loss of arsenic.

The same approach has been employed to characterize the data on the alloying elements-in China at this time these are tin and lead, using the benchmark of $1 \%$ to

Table 2 Definition of copper groups (arsenic, antimony, silver, nickel, Y-yes, N-no)

\begin{tabular}{lllll}
\hline Copper groups & \multicolumn{4}{l}{$\begin{array}{l}\text { Presence (yes)/absence (no): As, Sb, Ag } \\
\text { and Ni }\end{array}$} \\
\hline 1. Pure copper & $\mathrm{N}$ & $\mathrm{N}$ & $\mathrm{N}$ & $\mathrm{N}$ \\
2. As only & $\mathrm{Y}$ & $\mathrm{N}$ & $\mathrm{N}$ & $\mathrm{N}$ \\
3. Sb only & $\mathrm{N}$ & $\mathrm{Y}$ & $\mathrm{N}$ & $\mathrm{N}$ \\
4. Ag only & $\mathrm{N}$ & $\mathrm{N}$ & $\mathrm{Y}$ & $\mathrm{N}$ \\
5. Ni only & $\mathrm{N}$ & $\mathrm{N}$ & $\mathrm{N}$ & $\mathrm{Y}$ \\
6. As-Sb & $\mathrm{Y}$ & $\mathrm{Y}$ & $\mathrm{N}$ & $\mathrm{N}$ \\
7. Sb-Ag & $\mathrm{N}$ & $\mathrm{Y}$ & $\mathrm{Y}$ & $\mathrm{N}$ \\
8. Ag-Ni & $\mathrm{N}$ & $\mathrm{N}$ & $\mathrm{Y}$ & $\mathrm{Y}$ \\
9. As-Ag & $\mathrm{Y}$ & $\mathrm{N}$ & $\mathrm{Y}$ & $\mathrm{N}$ \\
10. Sb-Ni & $\mathrm{N}$ & $\mathrm{Y}$ & $\mathrm{N}$ & $\mathrm{Y}$ \\
$11 . \mathrm{As}-\mathrm{Ni}$ & $\mathrm{Y}$ & $\mathrm{N}$ & $\mathrm{N}$ & $\mathrm{Y}$ \\
12. As-Sb-Ag & $\mathrm{Y}$ & $\mathrm{Y}$ & $\mathrm{Y}$ & $\mathrm{N}$ \\
\hline
\end{tabular}


denote 'present'. We do this rather than using modern definitions of alloys because we find a greater diversity of composition in Bronze Age alloys, and we also believe that these 'non-standard' alloy compositions can contain significant information about the biographies of the objects. As with the trace elements, it is extremely important to carry out the second stage of the analysis, such as mapping, or plotting alloying element profiles. An extra line of information which can be extracted from the alloying data in this second stage of analysis is about the nature of the alloying practice (primary alloying vs. secondary alloying; Pollard et al. 2019a, b). If the tin concentrations of a metal assemblage present a symmetrical or unimodal pattern (similar to the shape of the normal distribution) in a histogram, it implies that the addition of tin is deliberately controlled by craftspeople (and therefore represents human intentionality). An irregular pattern of tin concentrations (or more often a skewed distribution with a preponderance of values close to the lower end) is more likely to represent an assemblage that includes objects made by the mixing or recycling of finished bronzes. This can lead to a wide range of tin concentrations in the final products, which we refer to as an assemblage of secondary alloys. The challenges attendant on comparing assemblages of different sizes have led us to develop a more statistically rigorous approach, using cumulative frequency distributions, which we have suggested might be used as representations of 'regional alloying practice' (Pollard et al. 2019a, b).

The third tool is specific to lead isotope data. The usual form of presentation is to produce a biplot of one lead isotope ratio against another, which is based on the original geochemical requirement to allow the calculation of the geological age of the deposit from the measured lead isotopes. We suggest that this method is not particularly suitable for presenting archaeological data, where there may be significant mixing of lead from different sources. A new way of plotting a single lead isotope ratio (we use ${ }^{206} \mathrm{~Pb} /{ }^{204} \mathrm{~Pb}$ ) against the inverse of the lead concentration in the object is proposed in Pollard and Bray (2015). This is a well-developed method in strontium isotope geochemistry, which has been applied previously to strontium in archaeological glasses (e.g. Degryse et al. 2006), and is well suited to the study of Chinese bronzes, since lead was added to the copper almost from the beginning of the use of bronze. It also resolves the debate about whether the lead isotopes are indicative of the source of lead or copper (Jin 2008, pp. 39-43), by combining lead concentration and lead isotope ratio in the same figure. Further, it is possible to colour-code the datapoints in such a diagram according to copper group, in which case all three types of information (lead isotopes, alloying as represented by lead concentration, and trace element pattern as represented by copper groups) can be practically presented in a single diagram.

Essentially, the Oxford system is a characterization method, which enables scholars to identify data structures which are archaeologically meaningful. However, what links the initial characterization results and final archaeological conclusions is a broader discussion. This is ultimately dependent on the integration and balancing of all the other available lines of archaeological information.

We think that applying the Oxford system to Bronze Age China has a variety of benefits as well as difficulties. Archaeologists have achieved remarkable insight into Bronze Age China, laying the groundwork for the application of the Oxford 
system. It should be noted that one of the defining characteristics of Bronze Age China is large-scale metal production, underpinned by an extremely high level of standardization (perhaps starting from Zhengzhou). This can be attested from not only the foundry remains and the bronze objects but also their chemical and isotopic patterns. Applying the Oxford system helps us quickly and systematically identify these patterns, particularly at an assemblage level. The provenance and supply network of raw metals is equally interesting, but it is then vital to trace further technological events through the history of the metal, particularly mixing and recycling. In theory, this can be well resolved by the Oxford system, which explicitly evaluates and compares the trace element patterns with those for major alloys, and lead isotope ratios. Alloying (tin and lead) was practised in China at a very early stage and the lead isotopic patterns are highly distinguished (common lead vs. highly radiogenic lead; Jin et al. 2017; Liu et al. 2018a). Both alloying data and lead isotopes could be useful for detecting - and even quantifying-mixing and recycling. In the case of Bronze Age China, the history of metal supply, movement and technology must move beyond a demand-supply perspective to encompass its social significance. This is mainly because early dynastic China produced a striking number of bronze ritual vessels to materialize the social order. The scientific investigation of the exchange, mixing and recycling of bronze ritual vessels will reinvigorate broader archaeological debates.

Using the Oxford system to interpret Chinese data entails certain difficulties. Firstly, although an extraordinary number of bronzes have been excavated in China, the scientific dataset is rather small. Other lines of evidence must therefore be used to cross-check and test the limited chemistry we have available. Moreover, further limitations emerge as many metal objects have received only one kind of scientific analysis. This makes the direct combination of data (e.g. lead concentration and lead isotopes) impossible. Unfortunately, the most significant dataset which contains analyses of all kinds (alloying, trace impurities and lead isotopes) is still the Sackler Collection, published in the 1990s (e.g. Bagley 1987; Rawson 1990). Secondly, the structure of arsenic distributions, which plays a pivotal role in the understanding of metal use and reuse in Bronze Age Europe (Bray and Pollard 2012; Radivojevic et al. 2018), cannot be applied to the Central Plains and Yangtze River valley. Here, the percentages of arsenic in the majority of bronzes appear too low $(\sim 0-0.3 \%)$, with only a few exceptions (over $5 \%$ ). Considering the analytical errors and the complexity of arsenic behaviour in various metallurgical processes, we must conclude that tracking recycling with arsenic loss in the Chinese context is very difficult. Thirdly, the type of lead added to the bronze could make it difficult to understand silver in the underlying copper. For instance, argentiferous lead, which contains relatively high concentrations of silver (up to $1 \%$ ), may impart a significant amount of silver to the alloy, potentially obscuring the trace element signal of the copper. The influence of lead on the copper group pattern can be tested by plotting $\mathrm{Ag}(\%)$ against $\mathrm{Pb}(\%)$, with a positive relationship indicating that alloying, rather than the copper ore, is responsible for any silver content. We can show that some lead employed by the Shang and Western Zhou was indeed argentiferous (Liu 2016, pp. 305, 309). The practical issue is that many chemical datasets on Chinese bronzes are either too small to support this kind of test, or do not publish the concentrations of silver. 


\section{Comparing the Metal at Zhengzhou and Panlongcheng}

Two major sources of data have been employed in this paper. That for Zhengzhou is from Tian (2013; also see Tian et al. 2013). In addition to 18 bronzes (all vessels) with only alloying data, 25 ritual bronze vessels have been analyzed with ICPOES for tin and lead and ICP-MS for trace elements and lead isotopes. The data for the Panlongcheng objects is from Chen et al. (2001), where SEM-EDS was used to examine samples for alloying elements $(\mathrm{Cu}, \mathrm{Sn}$ and $\mathrm{Pb})$ and NAA for the traces, and Sun et al. (2001) with ICP-MS for lead isotopes. Of these samples, 43 out of 50 are from vessels and the rest are from tools and weapons. Unfortunately, most of the analyzed objects are not included in the official archaeological report, and therefore the only typological information available here is the object class, such as vesseljia (單) or ding (鼎). The core characterization below has also been published in Liu et al. (2017).

When comparing data from different laboratories, techniques and analysts, we should, of course, try to assess the data quality. While carrying out a full evaluation may be difficult due to the incomplete record of analytical parameters, one aspect of the Oxford system that gives us confidence is that the minimum detection limits of both ICP-OES and ICP-MS are well below our benchmark of $0.1 \%$ for trace elements. Also, the metal assemblage at Panlongcheng has been analyzed by three teams. Cross-checking suggests that the tin and lead published by He are systematically lower those published by Chen et al. and Sun et al.; we have therefore chosen to exclude his data (Liu 2016, p. 166).

\section{Trace Elements in the Copper}

Figure 6 presents the distribution of copper groups at both Zhengzhou and Panlongcheng. The left side of the figure shows a high percentage of CG1 (clean) and CG2 (As-only) at both sites (see also the table in Fig. 6, which gives the percentage of the total number of objects from each site attributed to each group). However, the other four groups present at significant levels in the figure (CG 4, 5, 9 and 11) display substantial differences between the two assemblages, and suggest that the copper in use at Zhengzhou and Panlongcheng was not exactly the same. At Panlongcheng, $30 \%$ of the objects are assigned to groups which contain significant levels of nickel-either CG5 (Ni-only) or CG11 (As-Ni). Neither of these is strongly represented at Zhengzhou ( $<8 \%$ in total). Meanwhile, more than $35 \%$ of the objects at Zhengzhou contain traces of silver (CG 4 and 9) compared to less than $15 \%$ at Panlongcheng.

The difference illustrated by the distribution of copper groups is further reinforced when we look into the actual amounts of nickel and silver in the objects, as shown in Fig. 7. After removing tin and lead from the total and renormalizing the rest of the elements, objects from Panlongcheng are clearly distinguished by their higher concentrations of nickel. Very few of the objects $(n=2)$ in the Zhengzhou metal assemblage show nickel greater than $0.1 \%$. In comparison with nickel, 


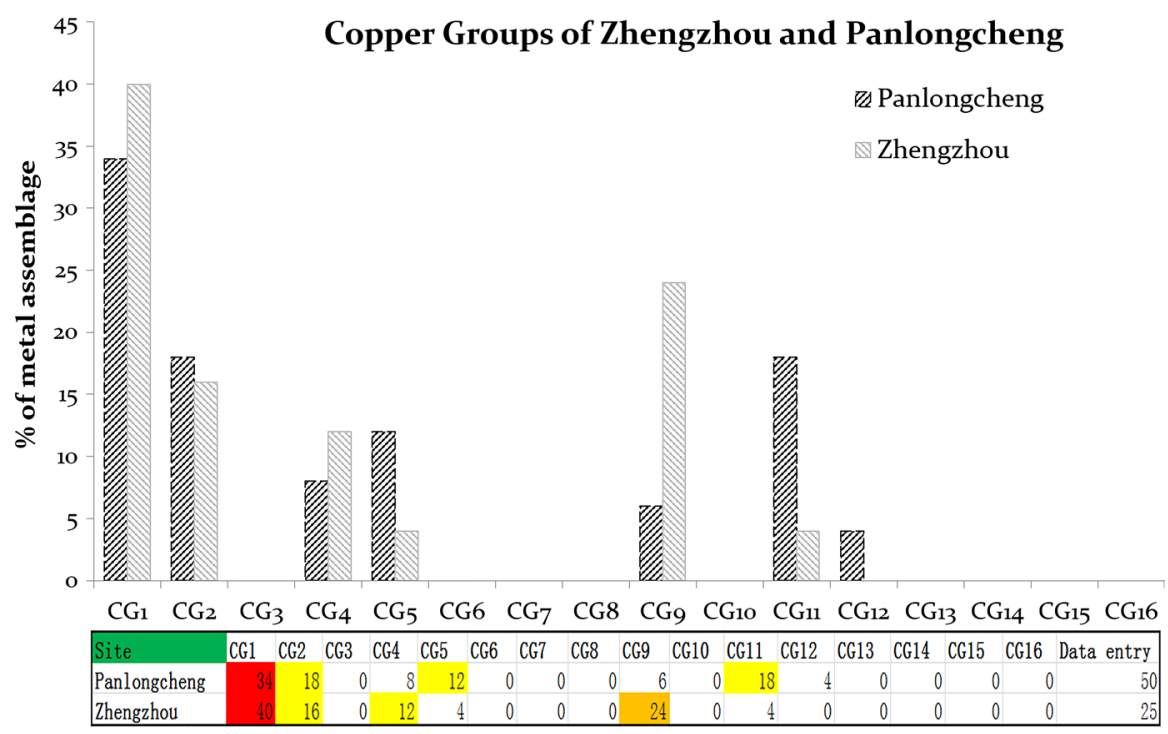

Fig. 6 Distribution of copper groups in Panlongcheng and Zhengzhou. (After Liu et al. 2017)

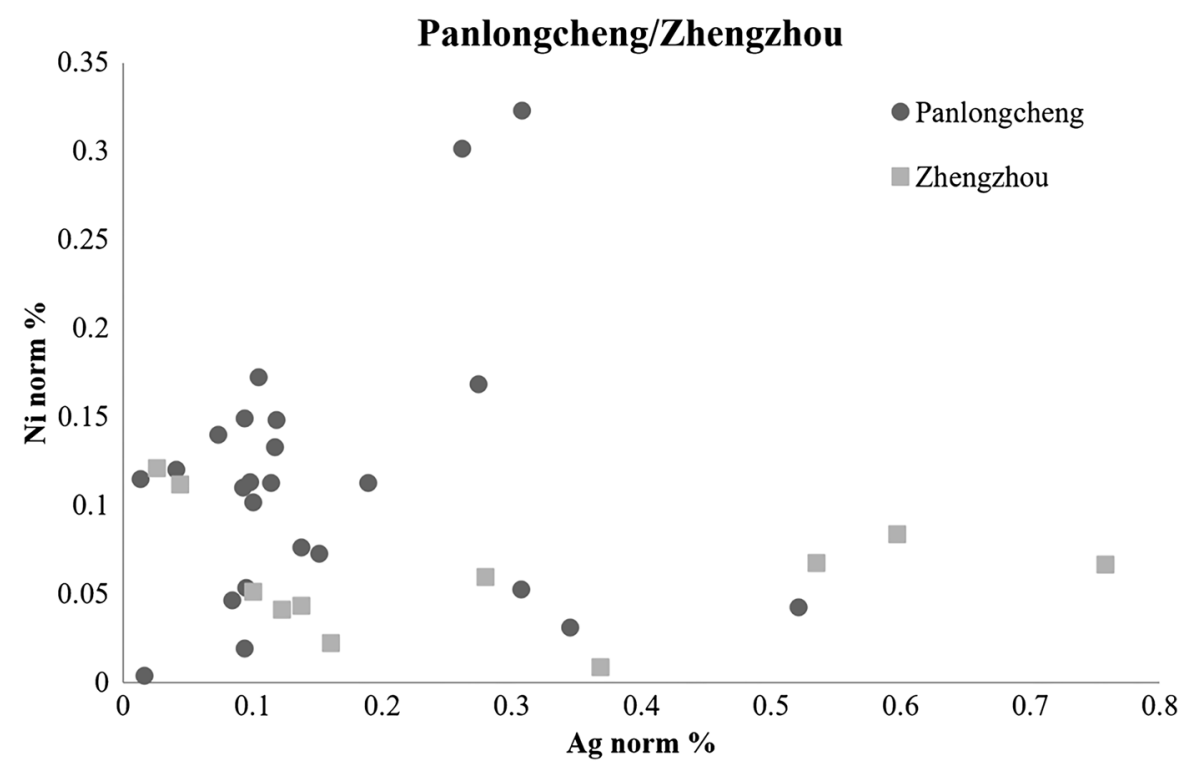

Fig. 7 Objects containing either nickel or silver from Zhengzhou/Panlongcheng. (After Liu et al. 2017)

the difference in silver percentage appears much less noticeable between the two sites. Although it is true that the three objects with the highest level of silver are all from Zhengzhou ( 0.54-0.76\%), six objects from Panlongcheng also contain silver 
between approximately $0.26 \%$ and $0.51 \%$, which makes the element of silver less diagnostic between these two datasets.

The significant presence of Ni-containing copper at Panlongcheng but not at Zhengzhou suggests that at least some of the copper in circulation at Panlongcheng was not sent to Zhengzhou, and that, therefore, the relationship between them is more complex than has been previously assumed. Is it possible that Ni-bearing copper was used only for 'local' objects at Panlongcheng, whereas other types of copper were transported to Zhengzhou? Although we do not think that ancient metalworkers could distinguish between copper containing small amounts of nickel and copper without nickel, it is possible that copper from one particular source (which happened to contain traces of nickel) was reserved for local use. If, for example, the nickelbearing copper had been reserved at Panlongcheng for one or two specific categories of bronze objects, it is possible that the metalworkers reserved a different category of metal for shipping to Zhengzhou. A comparison between the broad object typology (chariot fittings, tools, weapons and vessels) and copper group of the objects analyzed from Panlongcheng (Fig. 8) shows no clear relationship, although it must be noted that only the category of 'vessel' contains more than two objects. Breaking down this vessel category into ding, gu, jia, jun, zun, pan and 'fragments' and comparing with copper groups also reveals no significant patterns (Fig. 8). Based on the current (very limited) data it therefore seems that there is no relationship between copper group and object typology. We can therefore reject the suggestion that at Panlongcheng the nickel-bearing copper was used for any specific type of object, thereby making the lack of objects containing nickel-bearing copper at Zhengzhou more significant in terms of any postulated metal flow between the two sites.

While modern China has the largest annual production of nickel in the world, commercial nickel deposits are largely absent from the Central Plains area and the Yangtze River valley (Fig. 9). Although some sporadic nickel deposits around the Central Plains have been mentioned in Sun et al. (2014), they are either too deep for ancient mining (several hundred metres) or are iron-nickel deposits (e.g. Wang et al. 2006). A few nickel deposits can be found in the Qinling Mountains, but the majority lie to the west or northeast (Chen et al. 2009).

Reflecting the rarity of nickel deposits in the Central Plains and the Yangtze River valley, the FLAME database indicates that in China nickel-bearing copper objects are virtually absent from almost all of the sites from the Erlitou period to the Western Zhou dynasty. This is shown in Figs. 10 and 11 for the pre-Anyang and Anyang phases of the Shang. From these data we can argue that, in the pre-Anyang period, objects containing nickel are significant only at Panlongcheng and Hanzhong, and are relatively rare in the Central Plains, for instance at Erlitou, Zhengzhou and Anyang. In the later Anyang period, nickel-bearing copper is virtually absent, except in the northern borders of China with the steppe.

The site of Hanzhong is located in the Hanzhong basin, which is well connected to several regions through either the river system or mountain routes. Specifically, the Han River, the large branch of the Yangtze, offers a fast means of transportation between Hanzhong and Panlongcheng. Over 700 metal objects have been recovered at Hanzhong, mainly from areas around the counties of Chenggu and Yangxian (Zhao 2006). They include a number of object forms which can be divided into 


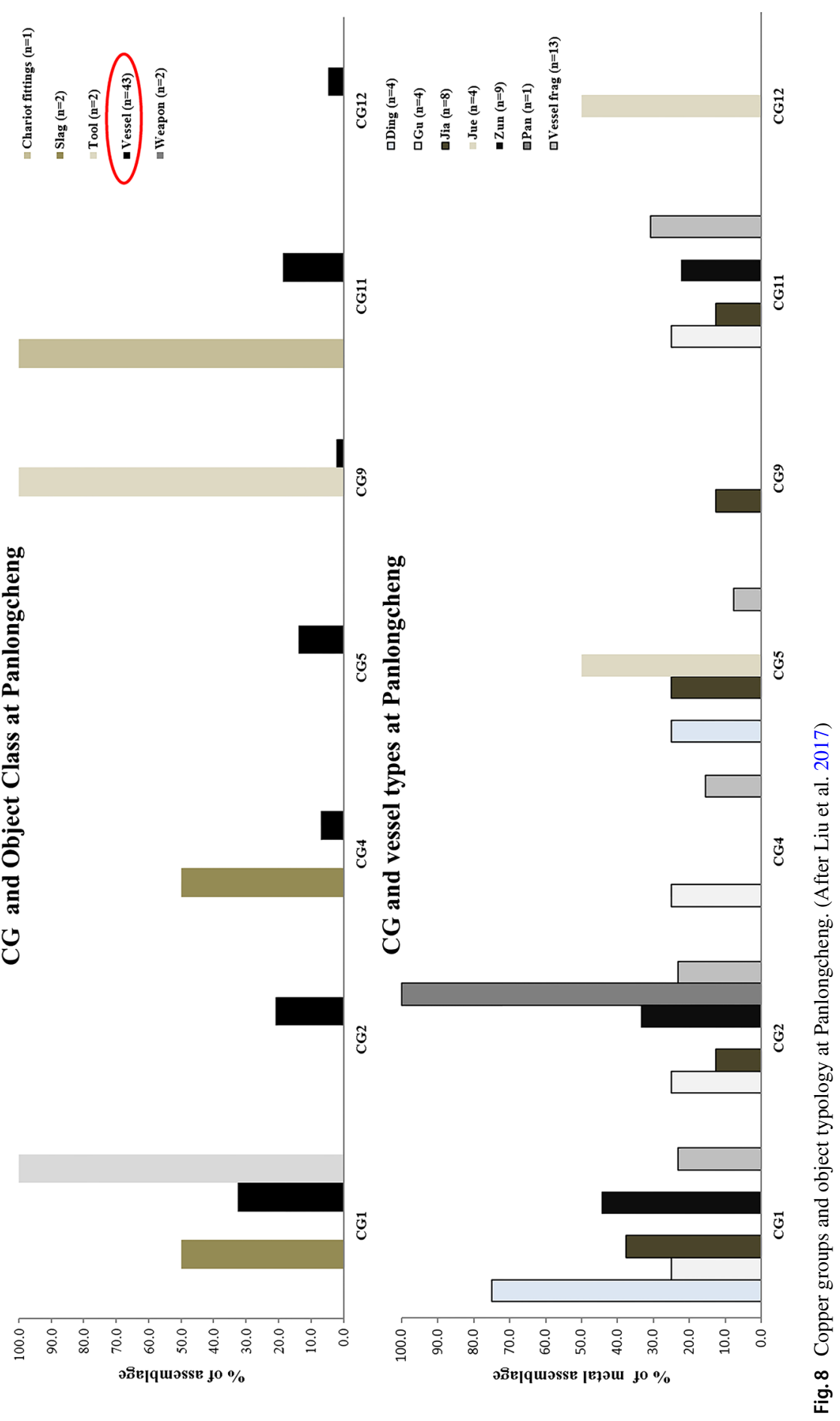




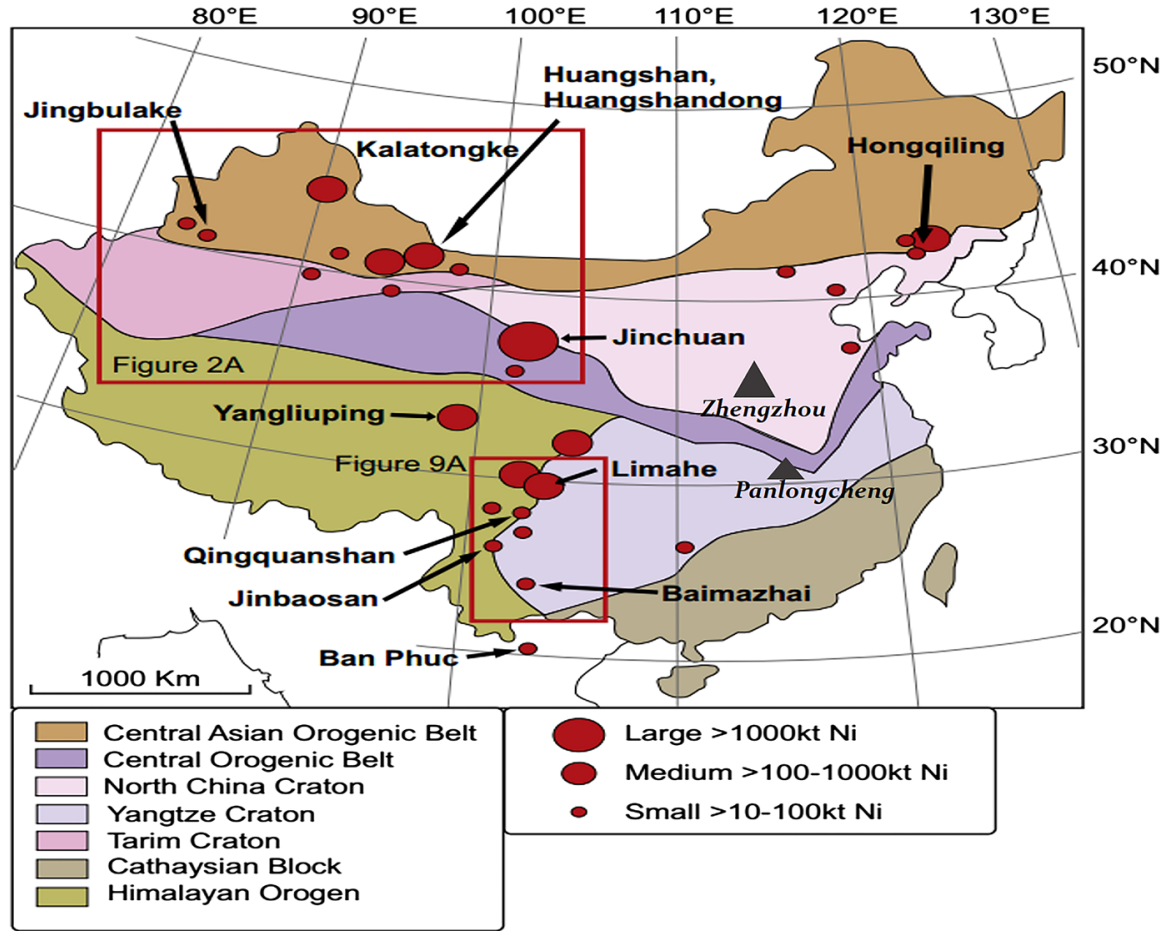

Fig. 9 Distribution of nickel deposits in China. (Adapted from Lightfoot and Evans-Lamswood 2015)

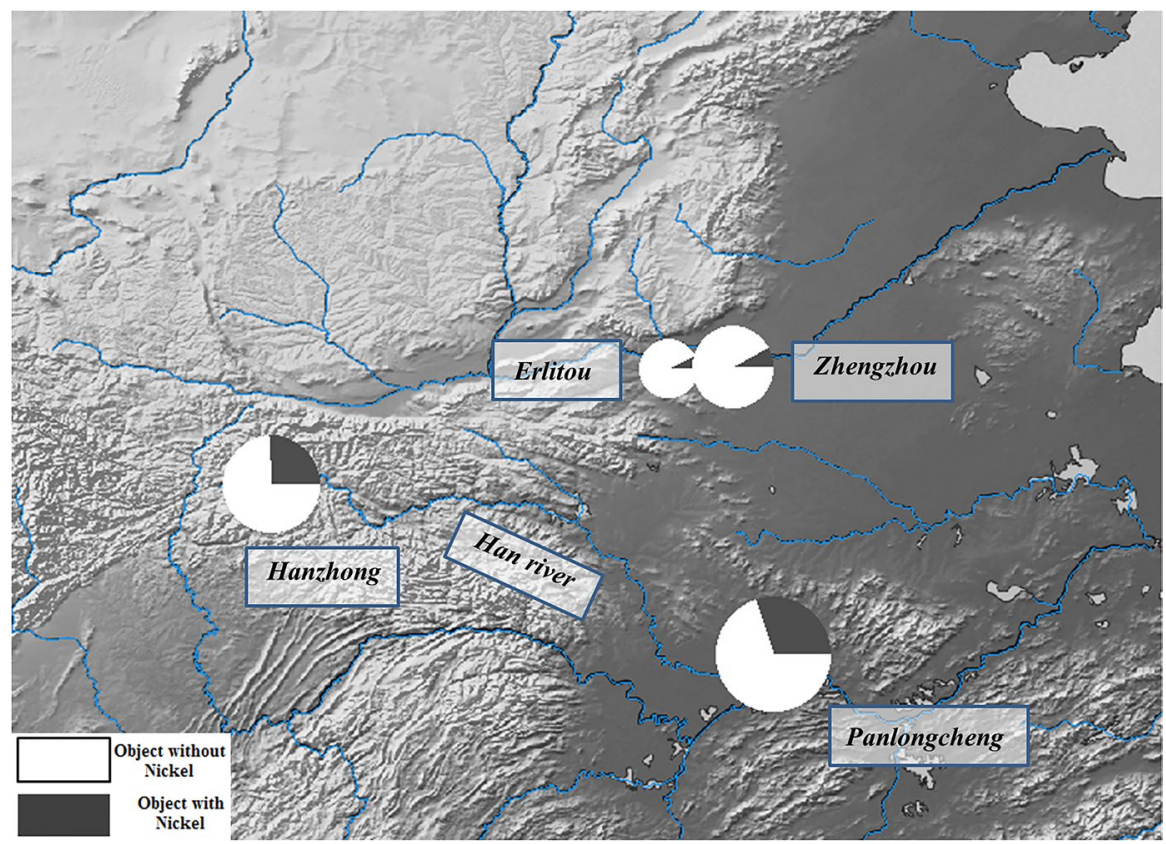

Fig. 10 Distribution of nickel-bearing objects in the pre-Anyang period (Liu 2016, p. 199) 


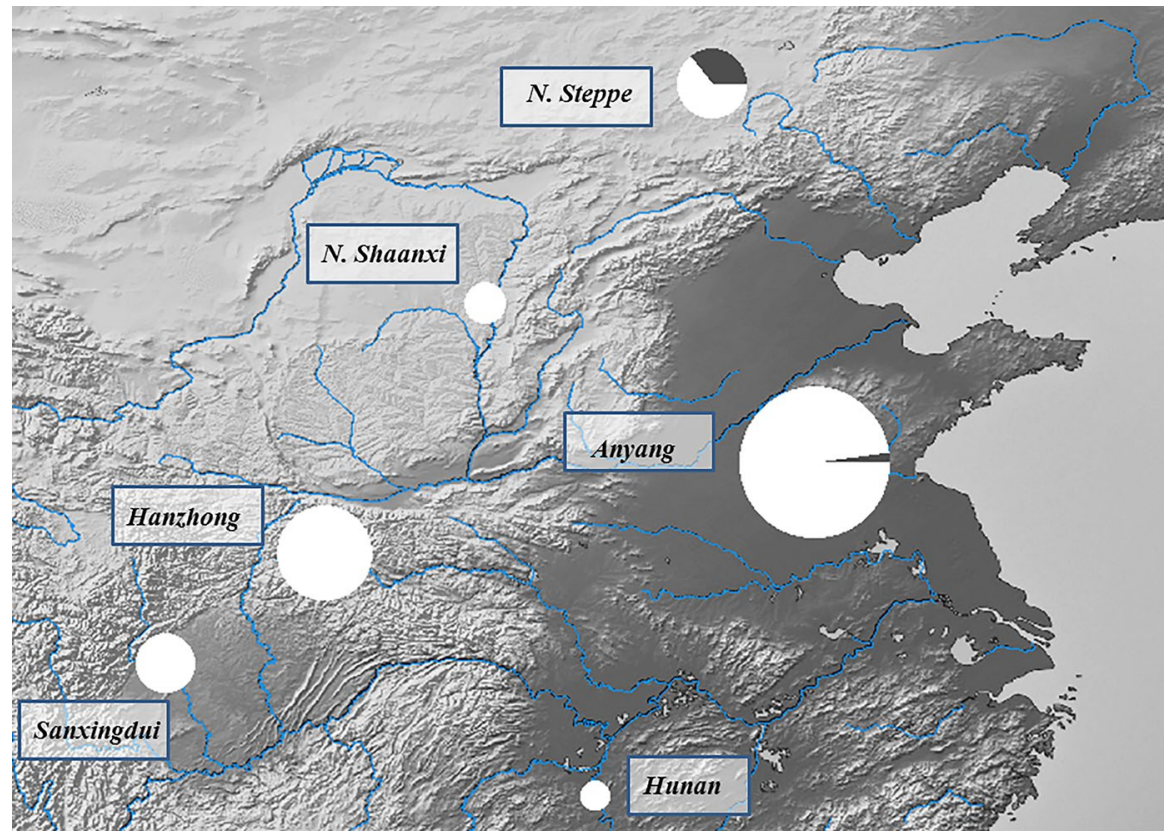

Fig. 11 Distribution of nickel-bearing objects in the Anyang period (Liu 2016, p. 199)

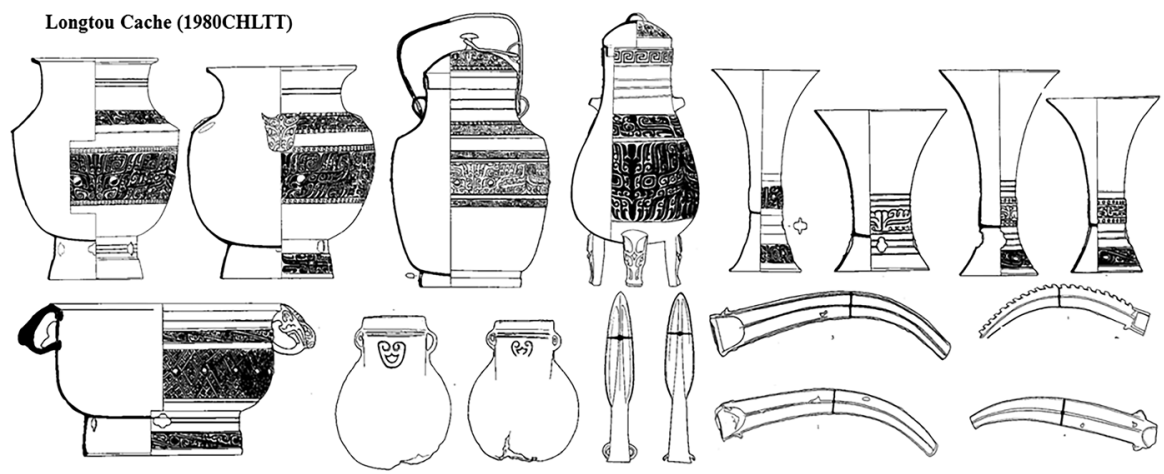

Longtou Cache (1981CHLTT)

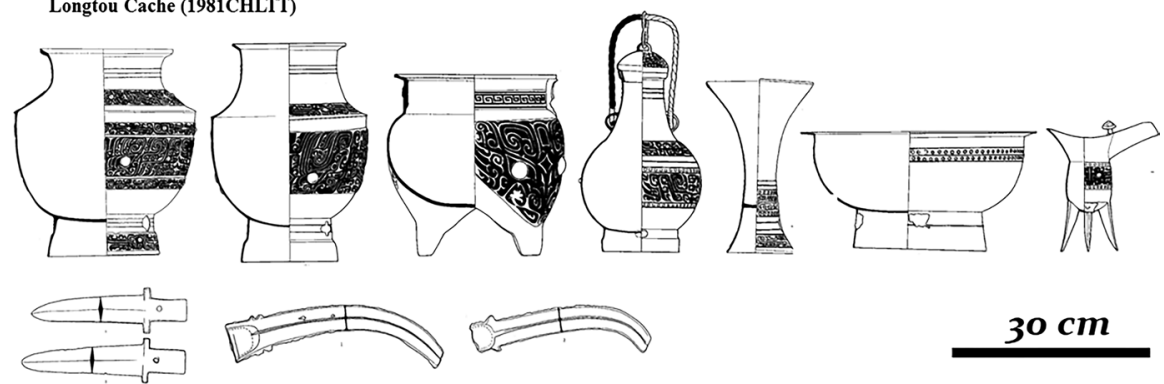

Fig. 12 Hanzhong metal assemblage dated to the Erligang period. (Adapted from Zhao 2006) 


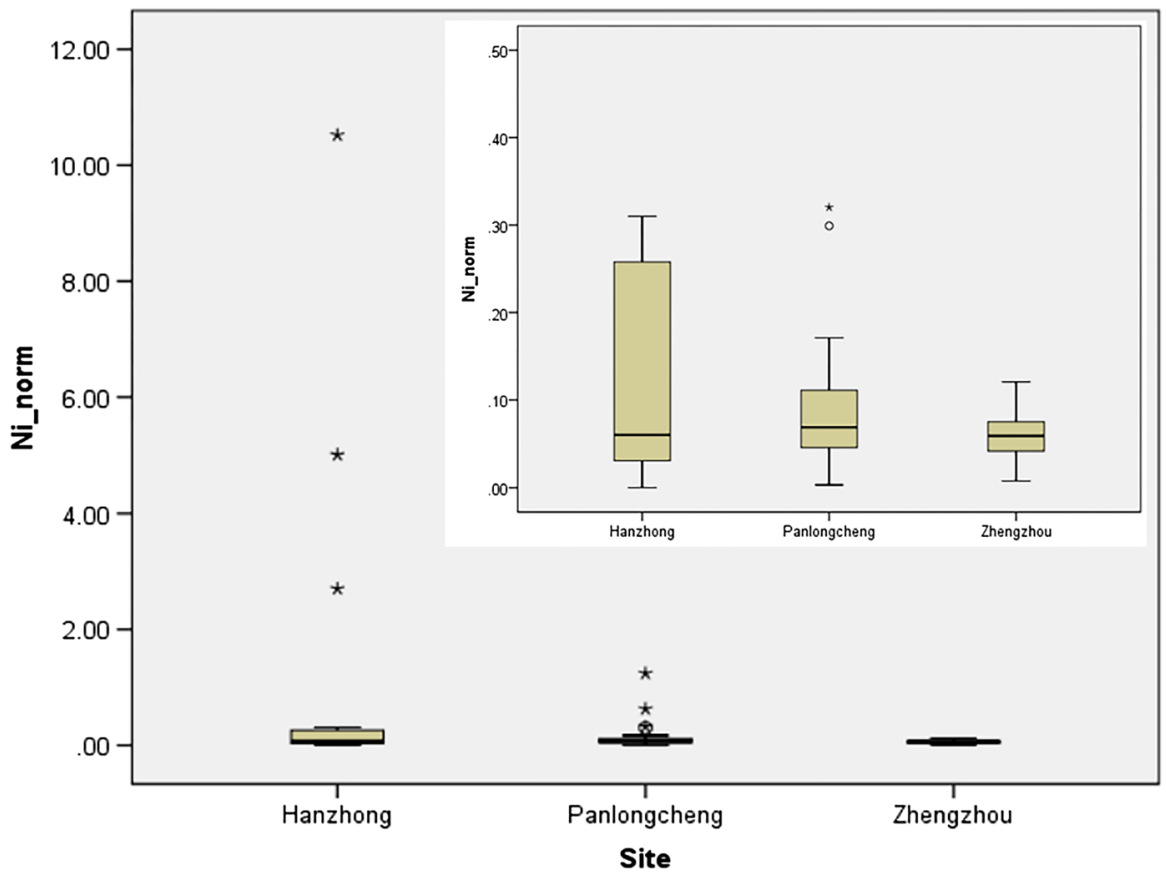

Fig. 13 Decreasing levels of nickel in the metal assemblages at Hanzhong, Panlongcheng and Zhengzhou

vessels, weapons and 'local styles' (Fig. 12; Zhao 2006; Cao 2006; Rawson 2011; Falkenhausen 2011).

In a broad context, it is interesting to see a conspicuous decrease in the levels of nickel (corrected for dilution) between Hanzhong, Panlongcheng and Zhengzhou (Fig. 13). The fact that Hanzhong has the highest levels of Ni might suggest that it is closer to the source of such copper than is Panlongcheng. The discovery of Erligang bronze vessels and weapons at both sites confirms that they were both connected to Zhengzhou, if not directly to each other, but the presence of nickel-bearing copper at these two sites but not significantly at Zhengzhou suggests that some direct connection may have existed between them, perhaps via the Han River. However, in contrast to Panlongcheng, the metal assemblage dated to the early Shang period at Hanzhong contains not only the typical Erligang bronze vessels and weapons but also modified copies and locally distinctive objects, the most obvious examples of which are the large sickles (lianxingqi, 镰形器) found in the Longtou caches of Hanzhong, each around half a metre long (Fig. 12).

In their major study of the early metal objects at Hanzhong (Chen 2009; Chen et al. 2009, 2019; Mei et al. 2009), Chen and colleagues emphasized that the people at Hanzhong were producing their own unique metal objects. Significantly, they also identified that these 'local' objects (e.g. the sickles) were made from nickel-bearing copper, and that some contain large amounts of nickel, up to c. 1-5\%. Whilst precise estimation of the earliest date for the use of these sickles at Hanzhong currently appears impossible, it is not hard to imagine that, if these sickles were transported 
by river to Panlongcheng, they might not have been very appealing objects. They could have been turned into bronze ritual vessels or weapons at Panlongcheng by recycling and mixing, through which process the nickel would have been introduced into the production system at Panlongcheng. Before accepting such a hypothesis, however, it is important to see whether any of the copper mines along the Yangtze River could have produced nickel-bearing copper, or if any other Erligang sites contain copper-based objects with nickel. This assessment can only be made when more data are published.

Although we have so far focused on the differences in nickel content between objects from Panlongcheng and Zhengzhou, it is important to note that (alongside other differences) there are also similarities between the two assemblages. The similarities are the high frequencies of CG1 (clean copper) and CG2 (As-only) at the two sites, together making up approximately $55 \%$ of each assemblage. It is important to emphasize that it is inherent in the copper group philosophy that we do not equate copper groups with specific sources of copper-objects within one copper group could come from more than one place, and one mine could produce copper of more than one group. Given that the majority of the previous literature has argued that Panlongcheng was established to transport copper resources from south to north, can we say that the similarity between Panlongcheng and Zhengzhou in terms of the frequency of CG1 and CG2 objects in their assemblages supports this archaeological observation?

Typological analysis of pottery and bronze suggests that the copper-mining activities along the middle Yangtze River are likely to have started around 1500 BC (Fig. 14). More support for this date comes from the existing radiocarbon dates remodeled within Oxcal (Fig. 14), which would be consistent with the establishment of Panlongcheng as an Erligang copper supply outpost. One question that is yet to be satisfactorily answered is whether the mines along the Yangtze could have produced copper with chemistry characterized by CG1 or CG2. Visual observation of the copper mineralization at Tongling and Tonglushan would suggest that smelting these ores could produce 'clean' copper (CG1), but we must wait for the publication of the detailed survey work now being carried out by Chinese archaeologists on the ancient mines in this area, and also for more analyses of objects from sites such as Xin'gan Dayangzhou. Based on the current database, however, it is more likely that CG 1 and 2 derive from the Yangtze region than from northern/northeastern parts of China (Liu 2016, p. 335). This would permit the suggestion that some of the copper found at Panlongcheng could have been sent to Zhengzhou, but would still require an explanation of how and why it was predominantly the CG1 and 2 copper that was so circulated.

The other important source of metal in the Shang period is the Zhongtiao Mountains in the southern part of modern Shanxi, west of Zhengzhou (Cui et al. 2009, 2012; Liang et al. 2009; Tong 2012). The Zhongtiao Mountains were almost certainly the key metal resource for the Erlitou site (Liu and Chen 2009, pp. 37-44). Therefore, in the absence of any chemical data from Zhongtiao, the chemistry of the metal objects from Erlitou may allow us to draw a general picture of the copper coming from Zhongtiao. Our re-analysis of the few chemical analyses of Erlitou objects containing trace element data published in Jin (2008) suggests that CG1 and 


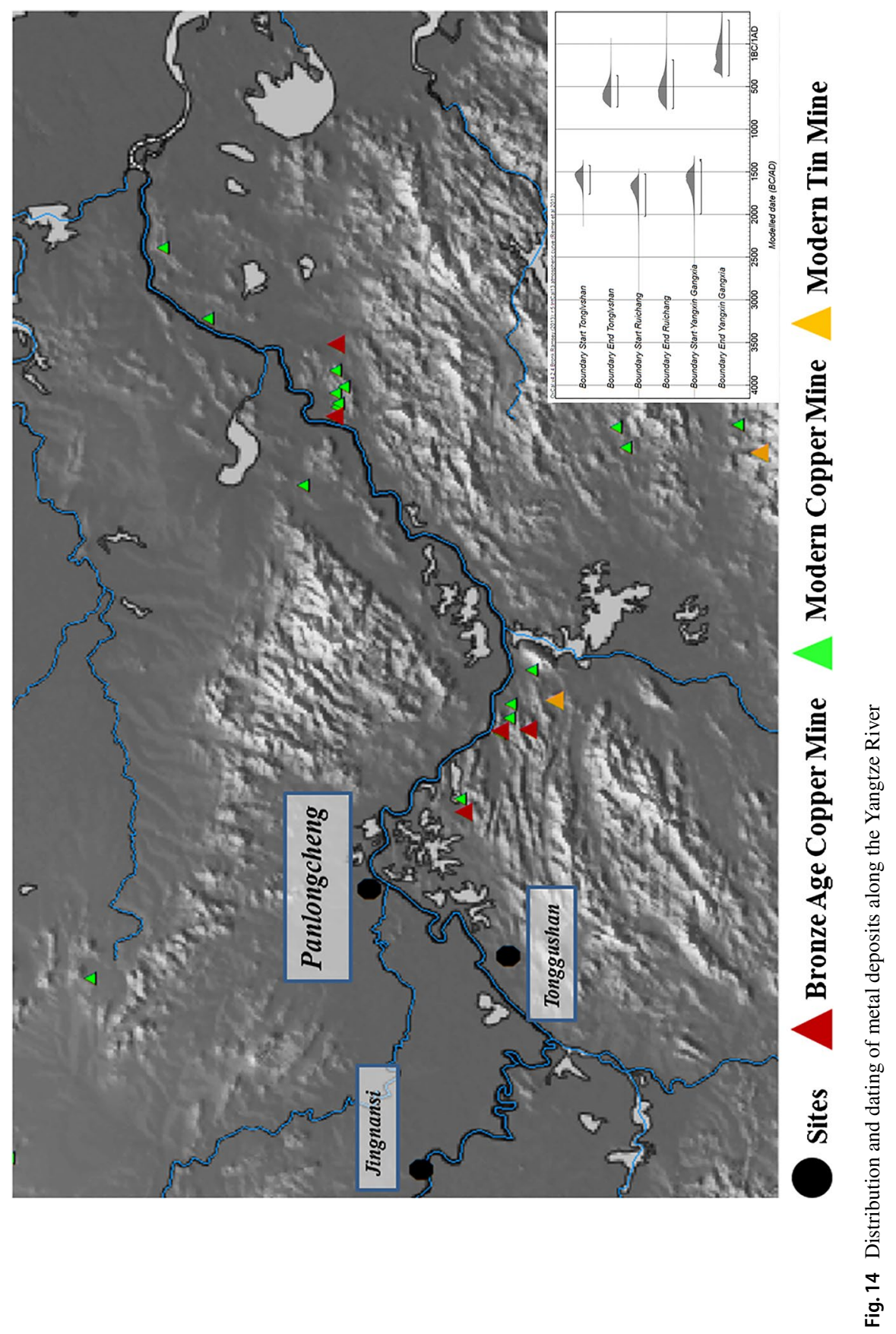


2 are actually of little importance at Erlitou (Liu 2016, p. 197). Together they add up to only $7.7 \%$ of the entire analyzed metal assemblage. The most significant copper groups discovered at Erlitou are CG4 (Ag-only, 30.8\%), CG9 (As-Ag, 23.1\%) and CG12 (As-Sb-Ag, 30.8\%). Interestingly, these copper groups, particularly CG4 and 9, are also present at Zhengzhou, possibly indicating a continuous use of the same source between Erlitou and Zhengzhou (which could be Zhongtiao). However, it would appear that Zhongtiao (as evidenced by the analyses from Erlitou) is unlikely to have been the source of CG 1 and 2 found at Panlongcheng and Zhengzhou.

\section{Tin Profile Analysis}

Whilst alloying technology has been discussed in Tian (2013; also Tian et al. 2013), more statistically robust tools are applied to the data. Figure 15 shows a comparison of the tin distribution in the metal assemblages from Erlitou, Zhengzhou and Panlongcheng. The average concentration of tin in the Panlongcheng vessels appears to be approximately 5\% higher than in the Zhengzhou vessels. This becomes more remarkable if one compares them both with tin in the alloys at Erlitou. Tin appears to have been used much more freely at Zhengzhou than at Erlitou, and we may therefore infer that Zhengzhou had a better supply network for tin than did its predecessor in the Central Plains. In the light of these observations, the striking amounts of tin seen in the Panlongcheng metal assemblage, which appear to be even higher than at Zhengzhou, certainly deserve further consideration.

Given the potential limitations of profile analysis discussed elsewhere (Pollard et al. 2019a, b), we have also applied a Kolmogorov-Smirnov (K-S) test to the distribution of tin within these three assemblages; this allows us to quantitatively compare the use of the alloying metal between the assemblages (for details of the

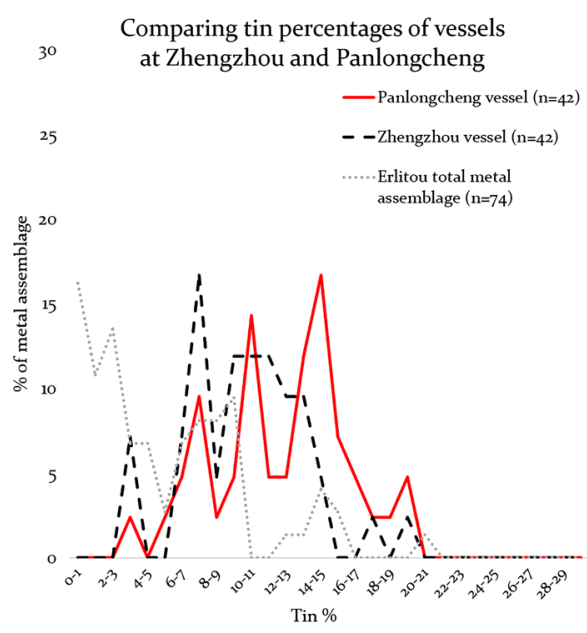

(a)

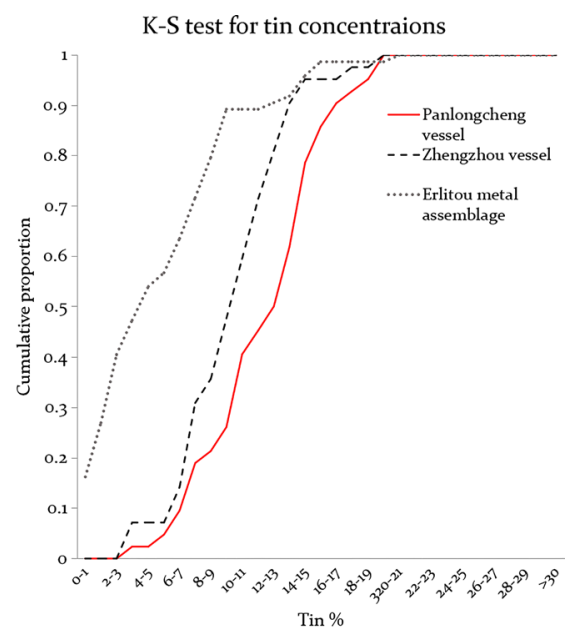

(b)

Fig. 15 Comparison of tin distribution between Erlitou, Zhengzhou and Panlongcheng in a skyline and b cumulative curve 
K-S test see Pollard et al. 2019a, b). This comparison shows a significant difference in the tin concentrations between the vessels from Zhengzhou and Panlongcheng, with Panlongcheng using more tin (Fig. 15). In this case, the observed maximum difference of the tin concentrations of objects at Panlongcheng and Zhengzhou is 0.42 , which is greater than the $\mathrm{K}-\mathrm{S}$ critical value of 0.34 (at $95 \%$ confidence). Under the table we also used normalized tin percentages (by extracting lead) and the ratio between tin and copper to test the sum unit issue. It can be concluded that the possibility of objects in the assemblages at these two sites representing the same range of percentages of tin is very low. Although this test is critically dependent on the nature of the objects included in the assemblages, we suggest on the basis of the current evidence that the vessels from Panlongcheng and Zhengzhou are made to different 'recipes', in terms of the alloying process with tin.

Although it is rather simplistic, we can postulate that one of the factors determining the amount of tin used to make an alloyed object is ease of access to tin supplies, on the assumption that people who have more convenient access to tin are able to put more into their objects. Greater ease of access could imply proximity to the tin mines themselves, or it could relate to access to stocks of tin transported directly to a centre of secondary metal production. Other factors could, of course, relate to the quality of the bronze required (which might dictate whether or not scrap metal could be used), and then there are factors such as the required colour and weight of the object. The fact that the vessels found at Panlongcheng have a higher average level of tin than those from Zhengzhou suggests that Panlongcheng may have had easier access to supplies of tin, which coincides with evidence from later tests and bronze inscriptions (Chen 2012; Yi 2013).

Modern geological surveys show that the tin mines are mostly distributed in the southern part of China, south of the Yangtze River valley (Liu and Chen 2001, p. 40; Fig. 16). Thus, the higher levels of tin in Panlongcheng could be explained by the relative proximity of the tin mines to the south $(\sim 100-200 \mathrm{~km})$. To the best of our current knowledge, the ancient tin mine at De'an in Jiangxi might have been the closest to Panlongcheng (Liu and Chen 2001, p. 39). A newly discovered site named Qiaomailing has yielded a variety of typical Erligang-style pottery (Rao and $\mathrm{Xu}$ 2016). This higher level of tin may also suggest that Panlongcheng had a role in supplying the Shang world with tin, in addition to (or instead of) copper.

\section{New Interpretations of Lead Isotope Data}

The new means of presenting lead isotope data in archaeological artefacts described above has been employed to re-characterize the lead isotope data from both Zhengzhou and Panlongcheng. Figure 17 shows a plot of ${ }^{206} \mathrm{~Pb} /{ }^{204} \mathrm{~Pb}$ versus $1 / \mathrm{Pb}$, and each data point is coded according to the copper group to which the object is allocated. A feature of such a presentation is that points to the left of 1 on the horizontal scale can be interpreted as relating to the isotopic composition of the added lead, whereas points to the right are likely to derive from traces of lead in the copper used. This figure immediately shows the presence in both assemblages of two important and well-known groups of lead isotopes in Chinese Shang bronzes, called 'radiogenic' 


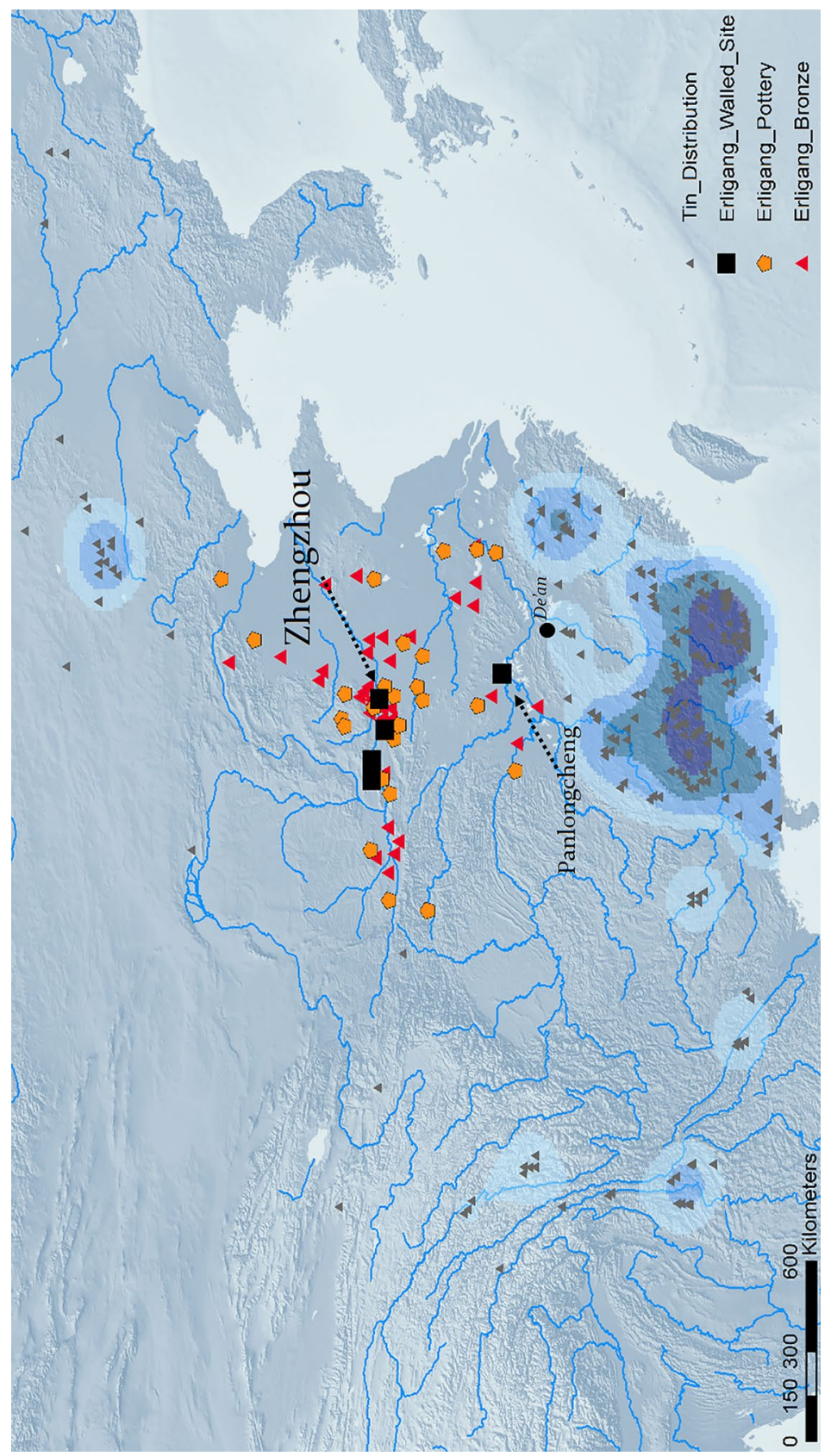

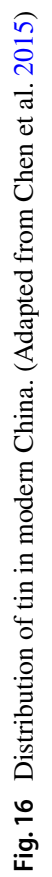




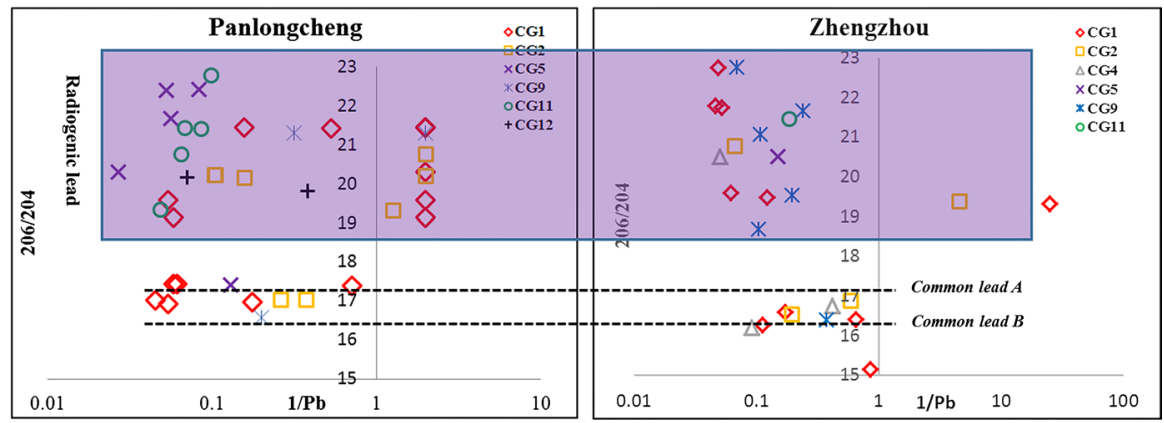

Fig. 17 Combining lead isotopes, lead percentages and copper groups (after Liu et al. 2017; the exact number of analyses here does not match that of Fig. 6 because lead isotopes of some objects are not reported)

and 'common' lead. A large number of objects from both assemblages lie between 19 and 23 on the ${ }^{206} \mathrm{~Pb} /{ }^{204} \mathrm{~Pb}$ axis, corresponding to 'radiogenic' lead, with no obvious distinction between the two assemblages. The values of the common lead, however, appear to be somewhat less compatible between the two sites. Most of the objects from Panlongcheng are over 17 in ${ }^{206} \mathrm{~Pb} /{ }^{204} \mathrm{~Pb}$ (here called common lead $\mathrm{A}$ ), but they are below 17 at Zhengzhou (common lead B). This probably means that the sources of the common lead used at Zhengzhou and Panlongcheng were different. What is equally significant is that, from this relatively limited data, we can see no systematic difference in lead isotopes between copper groups. This implies that the lead is added to the copper on a random basis, rather than there being some specific association between particular copper groups and lead isotope value. If this had been the case, it would perhaps suggest some geographical patterning to the production sites of the alloys - copper group $\mathrm{X}$ and $\mathrm{Pb}$ isotope composition $\mathrm{A}$ coming from one place, and copper group $\mathrm{Y}$ and isotope composition $\mathrm{B}$ coming from another. This does not appear to be the case.

To create a diagram such as Fig. 17, we need measurements of both the lead concentration and the lead isotope ratios in the same object. It is not always possible to obtain sufficient samples if we require both concentration and isotope values, so Jin et al. (2017) have proposed a further simplification to the methodology which uses only the isotope ratio (in this case ${ }^{206} \mathrm{~Pb} /{ }^{204} \mathrm{~Pb}$ ), but plots the samples in a temporal sequence (such as Erlitou, Erligang and Anyang); within each temporal block, the samples are in a random order. This very simple form of presentation allows changes over time to be seen in the isotopic value of the lead used, which might correspond to changes over time in the source of lead used.

Figure 18 reproduces all published lead isotopic data for Zhengzhou and Panlongcheng and also for the preceding Erlitou period (Jin 2008; Tian 2013; Sun et al. 2001; Peng et al. 2001). Some of the data points are associated with measurements of lead concentration on the same object, and are therefore included in Fig. 18, but the majority are simply lead isotope measurements. With more isotopic data, we can now see the trends within the common lead sources more clearly. An obvious difference can be observed along the line of ${ }^{206} \mathrm{~Pb} /{ }^{204} \mathrm{~Pb} \sim 16.5$ (common lead $\mathrm{B}$, Fig. 18), 


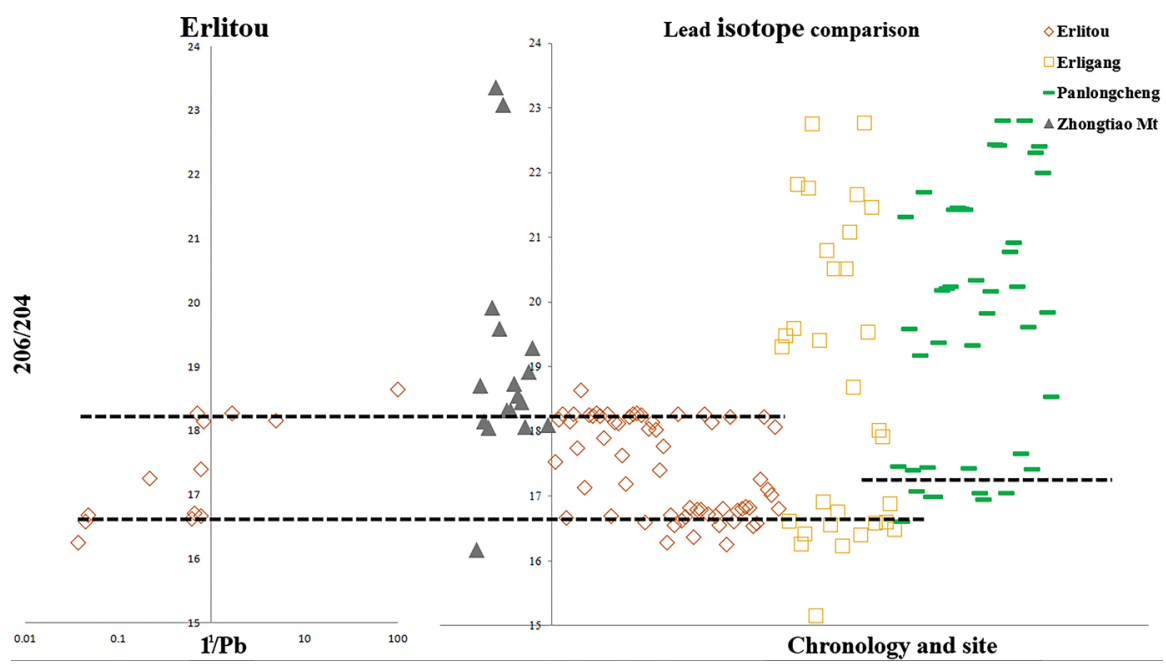

Fig. 18 Comparison of lead isotopes of copper ores from Zhongtiao mountain (Xu et al. 2005) and objects from Erlitou, Zhengzhou, Panlongcheng (the dotted lines here are to aid visualization)

which is undoubtedly present in Erlitou and Zhengzhou but not at Panlongcheng, suggesting a continuous tradition of the use of this lead source from Erlitou to Zhengzhou. In contrast, the second line of ${ }^{206} \mathrm{~Pb} /{ }^{204} \mathrm{~Pb} \sim 17.5$ (common lead $\mathrm{A}$ ) is conspicuously absent from Zhengzhou and very rare at Erlitou, but strongly present at Panlongcheng. From this we can conclude that the bronze casters at Zhengzhou and Panlongcheng were using different sources of common lead. This is a strong indicator that the lead being used at Panlongcheng was not the same as that in use at Zhengzhou.

The third strong line present in the Erlitou data $\left(\right.$ at ${ }^{206} \mathrm{~Pb} /{ }^{204} \mathrm{~Pb} \sim 18.25$ ) possibly represents a second source of lead used at Erlitou, which disappears in the Erligang period. Further consideration, however, suggests that the explanation may be less simple. It is known that leaded bronze (i.e., bronze with deliberately added lead) is almost ubiquitous in Bronze Age China from the Erligang period of the Shang onwards, but is less common in the preceding Erlitou period. It is possible, therefore, that the two lines in the Erlitou lead isotope data represent two alloying traditions - one with added lead-in which case the lead isotope values represent that of the added lead source - and one without added lead, in which case the lead value represents that in the source of the copper.

We can test this interpretation by using the very limited currently-available data on Erlitou bronzes that give us both $\mathrm{Pb}$ concentration and $\mathrm{Pb}$ isotope value. The left-hand side of Fig. 18 shows these data plotted as ${ }^{206} \mathrm{~Pb} /{ }^{204} \mathrm{~Pb}$ versus $1 / \mathrm{Pb}$, as discussed above. This strongly suggests that the points below (to the right of) $1 / \mathrm{Pb}=1$ (i.e., with $\mathrm{Pb}$ values $<1 \%$ ) have an isotopic ${ }^{206} \mathrm{~Pb} /{ }^{204} \mathrm{~Pb}$ value close to 18.25 , and those above (to the left of) $1 / \mathrm{Pb}=1$ (i.e., $\mathrm{Pb}>1 \%$ ) have another, around 16.5. This difference suggests that the interpretation given above might be correct, and that these two isotopic sources are in fact copper with traces of lead having an isotopic 
ratio around ${ }^{206} \mathrm{~Pb} /{ }^{204} \mathrm{~Pb}=18.25$, and an added lead source with ${ }^{206} \mathrm{~Pb} /{ }^{204} \mathrm{~Pb}$ around 16.5 .

The significance of this observation becomes clear especially when the published values of ${ }^{206} \mathrm{~Pb} /{ }^{204} \mathrm{~Pb}$ for chalcopyrite minerals (copper ores) from Zhongtiao Mountain are added (Xu et al. 2005). Unfortunately, there are as yet no published values for galena (lead ore) from Zhongtiao, but one might expect that the co-precipitated galena would have the same isotopic ratio as the traces of lead in the chalcopyrite. However, we may construct the following hypothesis, which of course requires further testing. A lead source with a value of ${ }^{206} \mathrm{~Pb} /{ }^{204} \mathrm{~Pb}=16.5$ was used by both Erlitou and Erligang smelters, but not at Panlongcheng. The other lead isotope value at Erlitou (18.25) represents the copper source used there, and could, from the modern data, have originated in the Zhongtiao Mountains. The switch from Erlitou to Zhengzhou at the beginning of the Erligang phase saw two apparent changes in metal supply. The first is that the copper used at Erlitou was no longer used-or perhaps the fact that Erligang bronzes generally contain added lead means that it is no longer possible to identify the lead signal from the copper. The second is that another source of lead became available, characterized by a 'radiogenic' isotope ratio. It is not known where this comes from, but it is significant that lead with similar values was also used at Panlongcheng. The widespread use of radiogenic lead in bronzes from the Erligang and Anyang periods of the Shang is one of the great mysteries of the Chinese Bronze Age, and has been extensively debated (Sun 2017; Jin et al. 2017; Liu et al. 2018a, b).

\section{Concluding Remarks}

There appears little doubt that, from the very beginning of its metallurgical activity, Panlongcheng chose to use Zhengzhou ritual vessels with their typical styles and casting technologies. Although it is not at all clear whether they were imported from Zhengzhou, or made locally by immigrants from Zhengzhou, or by local people imitating Erligang styles, the adoption of these Zhengzhou ritual bronzes reflects a close sociopolitical relationship between Panlongcheng and Zhengzhou. From the most recent archaeological findings, local metal production is certainly present at Panlongcheng, but as yet no elite bronze casting has been identified.

Applying the Oxford system to the published chemical and isotopic data reveals a series of similarities and differences in the metal objects from Zhengzhou and Panlongcheng, which represent different aspects of metal use:

- Trace elements On the one hand, we have demonstrated several differences between the metal in use at the two sites. The copper groups, based on trace element data, show that copper containing nickel was present at Panlongcheng but very rarely at Zhengzhou. Moreover, at the same time, the metal at Hanzhong also contained nickel, which could have been transported down the Han River and re-melted at Panlongcheng (since Hanzhong-style objects such as sickles are not found there). On the other hand, the significant proportion of Copper Group 
1 and 2 (clean copper and As-bearing copper) at both sites can be seen to represent a large shared metal circulation.

- Lead isotopes The same pattern-probably more telling-appears in the lead isotopic data. While both sites are heavily dependent on radiogenic lead, there is an isotopic difference in the sources of common lead used in the objects from Panlongcheng and Zhengzhou, suggesting that their lead supply might also have been partially different.

- Alloying elements The discussion of tin also indicates a significant difference, with Panlongcheng using, on average, more tin per vessel than Zhengzhou. This could imply that Panlongcheng had greater access to tin sources, which is geographically likely since these sources lie to the south of the Yangtze River.

These new comparative results have several immediate archaeological implications. The idea that metal was shipped from Panlongcheng to Zhengzhou, and finished bronze objects were received in return, must be reconsidered. Although it is true that Zhengzhou and Panlongcheng could have shared a significant amount of metal, it appears increasingly likely that they also had their own access to different sources of raw metal. In this light, the importance of Panlongcheng must go beyond simply being a transit depot, and the movement of metal in early Bronze Age China should be considered a multi-directional network. This provides new insights into the interaction between the middle Yangtze River and the Central Plains at this time.

\section{Future Perspectives}

This paper contributes only one dimension to the issue of movement of metal in early dynastic China. Completing the whole jigsaw puzzle requires more future work, particularly from the perspective of mining archaeology. A further avenue to be explored is the role of tin. If the sources of the copper and lead were not completely the same at Panlongcheng and Zhengzhou, what about the tin? Panlongcheng probably had easier access to tin than Zhengzhou on the evidence of the tin profiles, and also from its geographical proximity to the tin sources. Could the creation of the city at Panlongcheng have been required to secure supplies of tin (rather than copper) from the south? Tin is a major component of bronzes, and would also have been needed in vast quantities. There are no known sources of tin closer to Zhengzhou than those to the south of the Yangtze (those on the northern borders of China are much further away). Could Panlongcheng have existed to supply tin? If this proves to be true, we may find that tin was another impetus to the connectivity between north and south.

The major copper mines along the Yangtze are also worthy of more detailed investigation. Over the last 10 years, mining archaeology in China has been extremely fruitful (e.g. Li 2014); numerous mining and smelting sites have been revealed and offer a great deal of first-hand material for more detailed laboratory analysis. We should compare these large copper mines to the object assemblages, with the aim of resolving the issues of chronology and chemical signatures of ores, 
ingots, and objects. Chronology provides the elementary ruler and chemical analysis permits further comparative studies to test hypothetical links (e.g. direct transportation or mixing different sources).

We hope that reassessing the existing scientific database for Panlongcheng offers a useful case study. Further insights into the complex movement of metal in early dynastic China require other directions (East: Daxinzhuang, North: Gaocheng Taixi, West: Wei River Valley or Hanzhong). The movement of metal along the Yangtze River, for instance, Panlongcheng-Hanzhong, is very intriguing and the sites in between (e.g. Lujiahe) require further attention. As scientific techniques become increasing available, we hope that any analyses of metal objects in the future will include not only alloying elements, but more importantly, impurity data and lead isotopes. As it becomes increasingly difficult to obtain samples, we should look towards the legacy of our work, and ensure that a complete suite of valuable data can be passed on.

Acknowledgements This work has been supported by various funding sources, including the European Research Council Advanced Grant (FLAME, 1300505), the Santander Travel Fund, China Oxford Scholarship Fund, and an Oxford Clarendon PAG DPhil scholarship. We would like express our gratitude to Dr. Chris Doherty and Prof. Chen Jianli for their suggestions and comments, and to Mrs Chen Lixin and Mr. Su Xin who kindly took us to the site of Panlongcheng and discussed the most recent excavations. We are also very much indebted to Prof. Sir Barry Cunliffe and Prof. Jianjun Mei, who made a series of insightful suggestions on the Panlongcheng chapter as part of Ruiliang Liu's Ph.D. viva.

Open Access This article is distributed under the terms of the Creative Commons Attribution 4.0 International License (http://creativecommons.org/licenses/by/4.0/), which permits unrestricted use, distribution, and reproduction in any medium, provided you give appropriate credit to the original author(s) and the source, provide a link to the Creative Commons license, and indicate if changes were made.

\section{References}

An, J. (1961). 试论郑州商代城址-傲都 (Preliminary discussion on Zhengzhou Shang site-The capital of Ao). Wenwu, Z1, 73-80 (in Chinese).

An, Z. (1954). 1952 年秋季郑州二里冈发掘记 (Excavation record of Zhengzhou Erligang in the autumn of year 1952). Kaogu Xuebao, 2, 65-107 (in Chinese).

An, J. (1973). 郑州南关外商代遗址的发掘 (Excavation of Zhengzhou Nanguanwai Shang site). Kaogu Xuebao, 1, 65-92 (in Chinese with English abstract).

Bagley, R. W. (1977). P'an-lung-ch'eng: A Shang city in Hupei. Artibus Asiae, 39(3/4), 165-219.

Bagley, R. W. (1987). Shang ritual bronzes in the Arthur M. Sackler Collections. Washington: Arthur M. Sackler Foundation.

Bagley, R. W. (1999). Shang archaeology. In E. L. Shaughnessy \& M. Loewe (Eds.), The Cambridge history of ancient China: From the origins of civilization to 221 BC (pp. 124-231). Cambridge: Cambridge University Press.

Bagley, R. W. (2016). 反思盘龙城遗址的意义(Reflecting the significance of Panlongcheng). In Panlongcheng Museum \& The Centre of Bronze Age Civilisation of Wuhan University (Eds.), 盘 龙城与长江文明国际学术研讨会论文集 (Conference papers of Panlongcheng and the Yangtze River Civilisation) (pp. 1-2). Beijing: Science Press.

Bray, P., Cuénod, A., Gosden, C., Hommel, P., Liu, R., \& Pollard, A. M. (2015). Form and flow: The 'karmic cycle' of copper. Journal of Archaeological Science, 56, 202-209.

Bray, P., \& Pollard, A. M. (2012). A new interpretative approach to the chemistry of copper-alloy objects: Source, recycling and technology. Antiquity, 86(333), 853-867. 
Cao, W. (2006). Shang bronzes from Hanzhong. In W. Cao (Ed.), 汉中出土商代青铜器 (Shang bronzes discovered at Hanzhong) (pp. 45-86). Chengdu: Bashu Press.

Chen, G. (2012). 商代锡料来源初探 (Preliminary discussion on the source of tin in Shang dynasty). Kaogu, 6, 54-68 (in Chinese with English abstract).

Chen, J., Sun, S., Han, R., Chen, T., Zhai, T., Ban, B., et al. (2001). 盘龙城遗址出土铜器的微量元 素分析报告 (Report on the trace elements of bronzes excavated at Panlongcheng). In Hubei Institute of Archaeology (Ed.), 盘龙城: 1963-1994年考古发掘报告 (Panlongcheng: Excavation report for the period of 1963-1994) (pp. 559-573). Beijing: Wenwu Press (in Chinese).

Chen, K. (2009). 陕西汉中出土商代铜器的科学分析与制作技术研究 (Scientific analysis and technological studies of Shang bronzes discovered at Hanzhong). Ph.D. thesis, University of Science and Technology Beijing (in Chinese with English abstract).

Chen, K., Mei, J., Rehren, T., Liu, S., Yang, W., Martinón-Torres, M., et al. (2019). Hanzhong bronzes and highly radiogenic lead in Shang period China. Journal of Archaeological Science, 101, 131-139.

Chen, K., Rehren, T., Mei, J., \& Zhao, C. (2009). Special alloys from remote frontiers of the Shang Kingdom: Scientific study of the Hanzhong bronzes from southwest Shaanxi, China. Journal of Archaeological Science, 36(10), 2108-2118.

Chen, S. (2014). 盘龙城与铜绿山古矿治的关系 (The relationship between Panlongcheng and Tonglvshan mining activities). In T. Feng, Y. Liu, X. Yu, H. Tang, \& X. Chen (Eds.), 商代盘龙城学术研 讨会 (Conference on Shang Panlongcheng) (pp. 44-54). Beijing: Science Press (in Chinese).

Chen, X. (2015). 商代盘龙城 (Shangdai Panlongcheng). Wuhan: Wuhan Press (in Chinese).

Chen, Z., Wang, D., Sheng, J., Ying, L., Liang, T., Wang, C., et al. (2015). 中国锡矿成矿规律概要 (Summary of the formation of tin mines in China). Dizhi xuebao, 6, 1026-1037 (in Chinese with English abstract).

Cui, J., Wu, X., Tong, W., \& Zhang, S. (2009). 陕西垣曲商城出土部分铜器的科学分析研究 (Scientific analysis of some bronzes at Yuanqu Shang site). Kaogu yu wenwu, 6, 86-90 (in Chinese with English abstract).

Degryse, P., Schneider, J., Haack, U., Lauwers, V., Poblome, J., Waelkends, M., et al. (2006). Evidence for glass 'recycling' using $\mathrm{Pb}$ and $\mathrm{Sr}$ isotopic ratios and $\mathrm{Sr}$-mixing lines: The case of early Byzantine Sagalassos. Journal of Archaeological Science, 33, 494-501.

Du, J., \& Wang, X. (2004). 偃师商城遗址研究 (Study of Yanshi Shang site). Beijing: Science Press (in Chinese).

Falkenhausen, L. V. (2011). The Bronze Age in the upper Han River Basin: Some observations. In W. Cao (Ed.), 汉中出土商代青铜器 (Shang bronzes discovered at Hanzhong) (pp. 378-516). Chengdu: Bashu Press.

Fang, H. (2004). 大辛庄遗址的考古发现与研究 (The discovery and study of the Daxinzhuang site). Shandong daxue xuebao (zhexue shehui kexueban), 1, 7-12 (in Chinese with English abstract).

Fang, Q. (2016). 盘龙城在中原文明交流中的作用试析 (Preliminary discussion on the role of Panlongcheng in the communication with the Central Plains civilisation). In Panlongcheng Museum \& The Centre of Bronze Age Civilisation of Wuhan University (Eds.), 盘龙城与长江文明学术研讨 会论文集 (Conference papers of Panlongcheng and the Yangtze River Civilisation) (pp. 200-204). Beijing: Science Press (in Chinese with English abstract).

Fang, Y. (1999). 从三处窝藏看郑州商城为何王都 (The reason that Zhengzhou Shang site should be the capital: The evidence from the three bronze hoards). Kaogu yu wenwu, 3, 39-42 (in Chinese with English abstract).

Gao, D. (1985). 论盘龙城遗址的性质与作用 (Discussion on the nature and function of Panlongcheng). Jianghan kaogu, 1, 82-89 (in Chinese with English abstract).

Gao, Z. (1981). 商文化不过长江辩 (Debating on the Shang culture not reached Yangtze). Qiusuo, 2, 107-112 (in Chinese).

Guo, B. (1958). 湖北黄陂杨家湾的古遗址调查 (Survey of ancient sites at Yangjiawan, Huangpi, Hubei). Kaogu tongxun, 1, 56-58 (in Chinese).

Han, Y. (2016). 盘龙城遗址首次发现铸造遗物及遗迹 (The first discovery of casting remains at Panlongcheng). Jianghan Kaogu, 2, 36-39 (in Chinse with English abstract).

Henan Cultural Bureau. (1959). 郑州二里冈(Zhengzhou Erligang). Beijing: Science Press (in Chinese). Henan Institute of Archaeology. (2001). 郑州商城 (Zhengzhou Shangcheng). Beijing: Wenwu Press (in Chinese).

Henan Institute of Archaeology, \& Zhengzhou Institute of Archaeology. (1999). 郑州商代铜器害藏 (Shang bronze hoards at Zhengzhou). Beijing: Science Press (in Chinese). 
Henan Institute of Archaeology, \& Zhengzhou Museum. (1983). 郑州新发现商代窝藏青铜器 (New discovery of bronze hoard at Zhengzhu). Wenwu, 3, 49-59 (in Chinese).

Henan Provincial Museum. (1975). 郑州新出土的商代前期大铜鼎 (Newly discovered early Shang bronze Ding vessels at Zhengzhou). Wenwu, 6, 64-66 (in Chinese).

Hubei Institute of Archaeology. (2001). 盘龙城—1963-1994年考古发掘报告 (Excavation report of Panlongcheng during the period of 1963-1994). Beijing: Wenwu Press (in Chinese).

IA CASS. (1980). 殷墟妇好墓 (The Fuhao tomb at Yinxu). Beijing: Wenwu Press (in Chinese).

IA CASS (Institute of Archaeology, Chinese Academy of Social Science). (2003). 中国考古学夏商卷 (Chinese archaeology: Xia and Shang). Beijing: Chinese Social Science Press (in Chinese).

IA CASS, National Museum of China, \& Shanxi Provincial Institute of Archaeology. (1988). 夏县东下 冯 (The site of Dongxiafeng at Xia county). Beijing: Wenwu Press (in Chinese).

Jiang, H. (1976). 盘龙城与商朝的南土 (Panlongcheng and the Shang southern territory). Wenwu, 2, 42-46 (in Chinese with English abstract).

Jin, Z. (2008). 中国铅同位素考古 (Lead isotope archaeology in China). Beijing: Press of University of Science and Technology (in Chinese with English abstract).

Jin, Z., Liu, R., Rawson, J., \& Pollard, A. M. (2017). Revisiting lead isotope data in Shang and Western Zhou bronzes. Antiquity, 91(360), 1574-1587.

Kane, V. C. (1974). The independent bronze industries in the south of China contemporary with the Shang and Western Chou Dynasties. Archives of Asian Art, 28, 77-107.

Lan, W. (1955). 湖北黄陂县盘龙城发现古城址及石器等 (The discovery of ancient site and stone tools at Panlongcheng). Wewu cankao ziliao, 4, 118-119 (in Chinese).

Li, X. (2001). 盘龙城与商朝南土 (Panlongcheng and the Shang southern territory). In Hubei Institute of Archaeology (Ed.), 盘龙城: 1963-1994年考古发掘报告 (Panlongcheng: Excavation report for the period of 1963-1994) (pp. 650-655). Beijing: Wenwu Press (in Chinese).

Li, Y. (2014). 中原与北方地区早期青铜产业格局的初步探索 (The pattern of mining industry of Bronze Age central and northern China). Zhongguo Wenwubao Wenwu Kaogu Zhoukan, 005, 1-4.

Liang, H., Sun, S., Li, Y., \& Tong, W. (2009). 垣曲商城出土炉渣炉壁内金属颗粒及矿物组成的初步 研究 (Analysis of the metallic prills and minerals in the slags uncovered from the Yuanqu Shang site). Wenwu baohu уи kaogu kexue, 21(4), 18-30 (in Chinese with English abstract).

Lightfoot, P. C., \& Evans-Lamswood, D. (2015). Structural controls on the primary distribution of maficultramafic intrusions containing $\mathrm{Ni}-\mathrm{Cu}-\mathrm{Co}-(\mathrm{PGE})$ sulfide mineralization in the roots of large igneous provinces. Ore Geology Reviews, 64, 354-386.

Linduff, K. M., \& Mei, J. (2014). Metallurgy in ancient eastern Asia: Retrospect and prospects. In B. W. Roberts \& C. P. Thornton (Eds.), Archaeometallurgy in global perspective: Methods and syntheses (pp. 785-803). New York: Springer.

Liu, L., \& Chen, X. (2001). Cities and towns: The control of natural resources in early states. Bulletin of the Museum of Far Eastern Antiquities, 73, 5-47.

Liu, L., \& Chen, X. (2009). State formation in early China. London: Duckworth.

Liu, L., \& Chen, X. (2012). The archaeology of China: From the late Paleolithic to the early Bronze Age. Cambridge: Cambridge University Press.

Liu, R. (2016). Capturing changes: Applying the Oxford system to further understand the movement of metal in Shang China. Ph.D. thesis, University of Oxford.

Liu, R., Bray, P., Pollard, A. M., \& Hommel, P. (2015). Chemical analysis of ancient Chinese copperbased objects: Past, present and future. Archaeological Research in Asia, 3, 1-8.

Liu, R., Pollard, A. M., Rawson, J., \& Tang, X. (2017). 共性、差异与解读:运用牛津体系探究早商 郑州与盘龙城之间的金属流通 (Similarities and differences: Using Oxford system to further understanding the metal movement between Zhengzhou and Panlongcheng). Jianghan Kaogu, 3, 119-129 (in Chinese with English abstract).

Liu, R., Rawson, J., \& Pollard, A. M. (2018b). Beyond ritual bronzes: Identifying multiple sources of highly radiogenic lead across Chinese history. Scientific Reports, 8(1), 11770.

Liu, S. (2002). 老牛坡 (Laoniupo). Xi'an: Shaanxi Renmin Press (in Chinese).

Liu, S., Chen, K. L., Rehren, T., Mei, J. J., Chen, J. L., Liu, Y., et al. (2018a). Did China import metals from Africa in the Bronze Age? Archaeometry, 60(1), 105-117.

McKerrell, H., \& Tylecote, R. F. (1972). Working of copper-arsenic alloys in the Early Bronze Age and the effect on the determination of provenance. Proceedings of the Prehistoric Society, 38, 209-218.

Mei, J., Chen, K., \& Cao, W. (2009). Scientific examination of Shang-dynasty bronzes from Hanzhong, Shaanxi Province, China. Journal of Archaeological Science, 36(9), 1881-1891. 
Nan, P., Qin, Y., Li, T., \& Dong, Y. (2008). 湖北盘龙城出土部分商代青铜器铸造的分析 (The manufacturing place of some bronzes at Panlongcheng in Hubei). Wenwu, 8, 77-82 (in Chinese with English abstract).

National Museum of Chinese History, Shaanxi Institute of Archaeology, \& Yuanqu Museum. (1996). 垣 曲商城(一)1985-1986年度勘察报告 (Yuanqu Shang site I: Report on the survey of the period 1985-1986). Beijing: Science Press (in Chinese).

Peng, Z., Wang, Z., Rao, H., \& Xu, C. (2016). 从养麦岭遗址看盘龙城类型商文化对赣北地区的影响 (The influence of Shang Panlongcheng variant on the northern part of Jiangxi from the perspective of the site Qiaomailing). In Panlongcheng Museum and The Centre of Bronze Age Civilisation of Wuhan University (Ed.), 盘龙城与长江文明国际学术讨论会论文集 (Conference papers of Panlongcheng and the Yangtze River Civilisation) (pp. 242-251). Beijing: Wenwu Press (in Chinese with English abstract).

Peng, Z., Wang, Z., Sun, W., Liu, S., \& Chen, X. (2001). 盘龙城商代青铜器铅同位素示踪研究 (Lead isotopic provenance study of bronzes at Panlongcheng). In Hubei Institute of Archaeology (Ed.), 盘龙城: 1963-1994年考古发掘报告 (Panlongcheng: excavation report for the period of 19631994) (pp. 552-558). Beijing: Wenwu Press (in Chinese with English abstract).

Pollard, A. M., \& Bray, P. (2015). A new method for combining lead isotope and lead abundance data to characterise archaeological copper alloys. Archaeometry, 57(6), 996-1008.

Pollard, A. M., Bray, P., Hommel, P., Hsu, Y.-K., Liu, R., \& Rawson, J. (2017a). 利用牛津研究体系深化 对中国青铜器的认识 (Applying the Oxford system to further understand the movement of metal in Bronze Age China). Kaogu, 1, 95-106.

Pollard, A. M., Bray, P., Hommel, P., Hsu, Y.-K., Liu, R., \& Rawson, J. (2017b). Bronze Age metal circulation in China. Antiquity, 91, 674-687.

Pollard, A. M., Bray, P., Hommel, P., Liu, R., Pouncett, J., Saundera, M., et al. (2019a). Beyond provenance: New approaches to interpreting the chemistry of archaeological copper alloys. Leuven: Leuven University Press.

Pollard, A. M., Liu, R., Rawson, J., \& Tang, X. (2019b). Chinese bronzes: From alloy composition to alloying practices. Archaeometry, 61(1), 70-82.

Qiu, S. (2016). 浅论盘龙城灰烬沟遗迹 (Preliminary discussion on the burning ash trenches at Panlongcheng). Nanfang wenwu, 4, 32-39 (in Chinese with English abstract).

Radivojevic, M., Roberts, B. W., Pernicka, E., Stos-Gale, Z., Martinon-Torres, M., Rehren, T., et al. (2018). The provenance, use, and circulation of metals in the European Bronze Age: The state of debate. Journal of Archaeological Research, 27, 131-185.

Rawson, J. (1990). Western Zhou ritual bronzes from the Arthur M. Sackler Collections. Washington: Arthur M. Sackler Foundation.

Rawson, J. (1999). Western Zhou archaeology. In E. L. Shaughnessy \& M. Loewe (Eds.), The Cambridge history of ancient China: From the origins of civilization to 221 BC (pp. 352-449). Cambridge: Cambridge University Press.

Rawson, J. (2011). 装饰纹样与地域一汉中青铜器的个案 (Ornaments and regions: The case of Hanzhong bronzes). In J. Rawson (Ed.), Zuxian yu yongheng (Ancestors and eternity) (pp. 3-47). Beijing: Sanlian Shudian (in Chinese).

Rawson, J. (2015). China and the steppe: Arms, armour and ornaments. Orientations, 46, 28-35.

Rawson, J. (2017). China and the steppe: Reception and resistance. Antiquity, 91(356), 375-388.

School of History of Wuhan University, Hubei Institute of Archaeology, \& Panlongcheng Museum. (2016). 近年来盘龙城遗址考古工作的主要收获 (Major discoveries in recent Panlongcheng excavations). In Panlongcheng Museum \& The Centre of Bronze Age Civilisation of Wuhan University (Eds.), 盘龙城与长江文明国际学术研讨会论文集 (Conference papers of Panlongcheng and the Yangtze River Civilisation) (pp. 33-45). Beijing: Kexue chubanshe (in Chinese).

Shelach-Lavi, G. (2015). The archaeology of early China: From prehistory to the Han Dynasty. Cambridge: Cambridge University Press.

Shi, J. (2016). 盘龙城与长江中游的青铜文明 (Panlongcheng and the bronze civilisation along the middle Yangtze). Kaogu, 8, 75-85 (in Chinese with English abstract).

Song, H. (1983). 从盘龙城考古发现试探商楚关系 (The relationship between Shang and Chu from the perspective of Panlongcheng). Jianghan Kaogu, 2, 61-65 (in Chinese).

Steinke, K., \& Ching, C. (2014). Art and archaeology of the Erligang civilization. Princeton: Princeton University Press.

Sun, S., Han, R., Chen, T., Zhai, T., Ban, B., \& Tian, K. (2001). 盘龙城出土青铜器的铅同位素比测定 报告 (Lead isotopic provenancing of bronzes at Panlongcheng). In Hubei Institute of Archaeology 
(Ed.), 盘龙城: 1963-1994年考古与发掘报告 (Panlongcheng: Excavation report for the period of 1963-1994) (pp. 545-551). Beijing: Wenwu Press (in Chinese).

Sun, T., Wang, D., Qian, Z., Fu, Y., Chen, Z., \& Lou, D. (2014). 中国镍矿成矿规律初探 (Preliminary investigation into the formation of nickel mines in China). Acta Geologica Sinica, 88(12), 22272251 (in Chinese with English abstract).

Sun, Z. (2017). 论商时期中原文化势力从南方的消退 (Discussing the retreat of the Shang culture from the south). Ph.D. thesis, University of Wuhuan (in Chinese with English abstract).

Tian, J. (2013). 郑州地区出土二里冈铜器研究 (The study of the Erligang bronzes at Zhengzhou). Ph.D. thesis, University of Science and Technology China, Hefei.

Tian, J., Jin, Z., \& Qi, Y. (2013). 郑州二里岗期青铜礼器的合金成分研究 (Alloying composition of Zhengzhou Erligang bronzes). Zhongyuan wenwu, 2, 90-96 (in Chinese with English abstract).

Tong, W. (2012). 垣曲商城与中条山的铜矿资源 (The Yuanqu Shang site and the copper resource in the Zhongtiao mountains). In School of Archaeology and Museology of Beijing University (Ed.), 考古 学研究 (九) (The study of archaeology IX) (pp. 346-361). Beijing: Science Press (in Chinese with English abstract).

Wang, H. (2014). China's first empire? Interpreting the material record of the Erligang expansion. In D. C. Y. Ching \& K. Steinke (Eds.), Art and archaeology of the Erligang civilization (pp. 67-97). Princeton: Princeton University Press.

Wang, J. (2016). 盘龙城的考古概况与收获 (The overview and results of the Panlongcheng archaeology). In Panlongcheng Museum \& The Centre of Bronze Age Civilisation of Wuhan University (Eds.), 盘龙城与长江文明国际学术研讨会论文集(Conference papers of Panlongcheng and the Yangtze River Civilisation) (pp. 10-17). Princeton: Science Press (in Chinese).

Wang, J., Chen, Y., Li, S., Wang, G., \& Mi, M. (2006). 河南周安铜镍矿床的地址特征及成因分析 (Geology and genesis of the Zhou'an PGE-Cu-Ni deposit, Henan province). Kuangwu yanshi, 26(3), 31-37 (in Chinese with English abstract).

$\mathrm{Xu}$, S. (2003). 从盘龙城遗址看商文化在长江中游地区的发展 (The development of the Shang culture along the middle Yangtze River from the perspective of Panlongcheng). Jianghan kaogu, 1, 40-44 (in Chinese with English abstract).

Xu, W., Wang, L., Li, H., \& Guo, X. (2005). 中条山铜矿床同位素地球化学研究 (Geochemical and geoisotopic study of the copper source in the Zhongtiao Mountains). Acta Geoscientica Sinica, 26(Zengkan), 130-133 (in Chinese with English abstract).

Yi, D. (2013). 科技考古视野下的商王朝锡料来源与'金道锡行' (The source of tin and the 'coppertin road' of the Shang dynasty from the perspective of archaeometry). Zhongguo shehui kexue, 5, 162-184 (in Chinese with English abstract).

Yuan, G., \& Qin, X. (2000). 河南焦作府城遗址发掘报告 (The excavation report of Jiaozuo Fucheng in Henan). Kaogu Xuebao, 4, 501-536 (in Chinese).

Zang, C. (2003). 盘龙城商代青铜器容器的初步考察 (A preliminary study of the bronze vessels at Panlongcheng). Jianghan kaogu, 1, 45-51 (in Chinese with English abstract).

Zhang, C. (2014a). 盘龙城的性质——个学术史的回顾 (The nature of Panlongcheng: A review of academic history). In T. Feng, Y. Liu, X. Yu, H. Tang, \& X. Chen (Eds.), 商代盘龙城学术研讨会 论文集 (Conference on Shang Panlongcheng) (pp. 123-129). Beijing: Science Press (in Chinese with English abstract).

Zhang, C. (2014b). Erligang: A perspective from Panlongcheng. In K. Steinke \& D. C. Y. Ching (Eds.), Art and archaeology of the Erligang civilization (pp. 51-63). Princeton: Princeton University Press.

Zhang, C. (2017). 龙山-二里头: 中国史前文化格局的改变与青铜时代全球化的形成 (LongshanErlitou cultures: Changing cultural patterns in prehistoric China and the emergence of the globalisation in the Bronze Age). Wenwu, 6, 50-59 (in Chinese with English abstract).

Zhang, C., Pollard, A. M., Rawson, J., Huan, L., Liu, R., \& Tang, X. (2019). China's major Late Neolithic centres and the rise of Erlitou. Antiquity, 93(369), 588-603.

Zhao, C. (2006). 城洋青铜器 (Bronze assemblage at Chenggu and Yang county). Beijing: Science Press (in Chinese).

Zou, H. (1956). 试论郑州新发现的殷商文化遗址 (Preliminary discussion of the newly-discovered late Shang sites at Zhengzhou). Каogu хиеbao, 3, 77-103 (in Chinese).

Zou, H. (1978). 郑州商城即汤都毫说 (The Zhengzhou Shang site at the capital Bo). Wenwu, 2, 69-71 (in Chinese).

Publisher's Note Springer Nature remains neutral with regard to jurisdictional claims in published maps and institutional affiliations. 